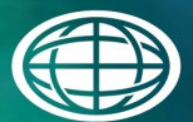

Savannah River

National Laboratory ${ }^{m}$

OPERATED BY SAVANNAH RIVER NUCLEAR SOLUTIONS

\title{
Method Development for Determining the Hydraulic Conductivity of Fractured Porous Media
}

Kenneth L. Dixon

Ralph L. Nichols

September 2013 
SRNL-STI-2013-00522

Revision 0

\section{DISCLAIMER}

This work was prepared under an agreement with and funded by the U.S. Government. Neither the U.S. Government or its employees, nor any of its contractors, subcontractors or their employees, makes any express or implied:

1. warranty or assumes any legal liability for the accuracy, completeness, or for the use or results of such use of any information, product, or process disclosed; or

2. representation that such use or results of such use would not infringe privately owned rights; or

3. endorsement or recommendation of any specifically identified commercial product, process, or service.

Any views and opinions of authors expressed in this work do not necessarily state or reflect those of the United States Government, or its contractors, or subcontractors.

\section{Printed in the United States of America \\ Prepared for U.S. Department of Energy}


Keywords: Saltstone, fractured permeability, radioactive waste, permeameter, outflow extractor

Retention: Permanent

\section{Method Development for Determining the Hydraulic Conductivity of Fractured Porous Media}

Kenneth L. Dixon

Ralph L. Nichols

September 2013

Prepared for the U.S. Department of Energy under contract number DE-AC09-08SR22470. 
SRNL-STI-2013-00522

Revision 0

\section{EXECUTIVE SUMMARY}

Plausible, but unvalidated, theoretical model constructs for unsaturated hydraulic conductivity of fractured porous media are currently used in Performance Assessment (PA) modeling for cracked saltstone and concrete (Flach 2011). The Nuclear Regulatory Commission (NRC) has expressed concern about the lack of model support for these assumed Moisture Characteristic Curves (MCC) data, as noted in Requests for Additional Information (RAIs) PA-8 and SP-4 (Savannah River Remediation, LLC, 2011). The objective of this task was to advance PA model support by developing an experimental method for determining the hydraulic conductivity of fractured cementitious materials under unsaturated conditions, and to demonstrate the technique on fractured saltstone samples. The task was requested through Task Technical Request (TTR) HLW-SSF-TTR-2012-0016 and conducted in accordance with Task Technical \& Quality Assurance Plan (TTQAP) SRNL-TR-2012-00090.

Preliminary method development previously conducted by Kohn et al. (2012) identified transient outflow extraction as the most promising method for characterizing the unsaturated properties of fractured porous media. While the research conducted by Kohn et al. (2012) focused on fractured media analogs such as stacked glass slides, the current task focused directly on fractured saltstone. For this task, four sample types with differing fracture geometries were considered: 1) intact saltstone, 2) intact saltstone with a single saw cut, smooth surface fracture, 3) micro-fractured saltstone (induced by oven drying), and 4) micro-fractured saltstone with a single, fully-penetrating, rough-surface fracture.

Each sample type was tested initially for saturated hydraulic conductivity following method ASTM D 5084 using a flexible wall permeameter. Samples were subsequently tested using the transient outflow extraction method to determine cumulative outflow as a function of time and applied pressure. Of the four sample types tested, two yielded datasets suitable for analysis (sample types 3 and 4). The intact saltstone sample (sample type 1) did not yield any measureable outflow over the pressure range of the outflow test $\left(0-1000 \mathrm{~cm} \mathrm{H}_{2} \mathrm{O}\right)$. This was expected because the estimated air entry pressure for intact saltstone is on the order of 100,000 $\mathrm{cm} \mathrm{H}_{2} \mathrm{O}$ (Dixon et al., 2009). The intact saltstone sample with a single saw cut smooth surface fracture (sample type 2) did not produce useable data because the fracture completely drained at less than $10 \mathrm{~cm} \mathrm{H}_{2} \mathrm{O}$ applied pressure.

The cumulative outflow data from sample types 3 and 4 were analyzed using an inverse solution of the Richard's equation for water flow in variably saturated porous media. This technique was implemented using the computer code Hydrus-1D (Šimůnek et al., 2008) and the resulting output included the van Genuchten-Mualem water retention and relative permeability parameters and predicted saturated hydraulic conductivity (Van Genuchten, 1980; Van Genuchten et al., 1991). Estimations of relative permeability and saturated conductivity are possible because the transient response of the sample to pressure changes is recorded during the multi-step outflow extraction test. Characteristic curves were developed for sample types 3 and 4 based on the results of the transient outflow method and compared to that of intact saltstone previously reported by Dixon et al. (2009).

The overall results of this study indicate that the outflow extraction method is suitable for measuring the hydraulic properties of micro-fractured porous media. The resulting cumulative outflow data can be analyzed using the computer code Hydrus-1D to generate the van Genuchten curve fitting parameters that adequately describe fracture drainage. The resulting characteristic curves are consistent with blended characteristic curves that combine the behaviors of low pressure drainage associated with fracture flow with high pressure drainage from the bulk saltstone matrix. 


\section{TABLE OF CONTENTS}

LIST OF TABLES. viii

LIST OF FIGURES viii

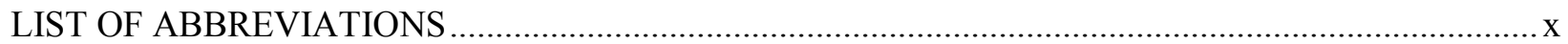

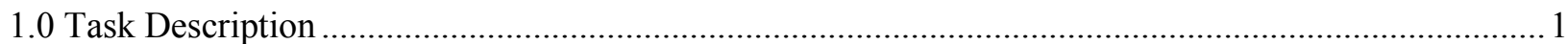

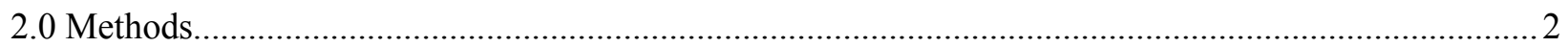

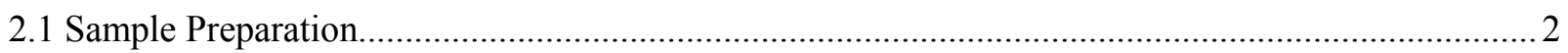

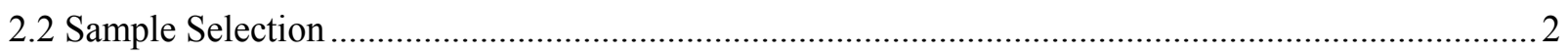

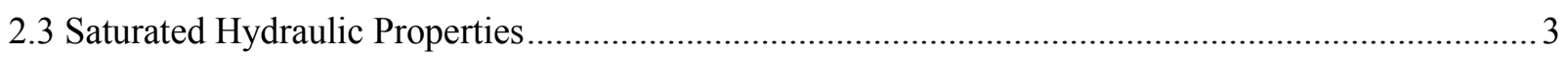

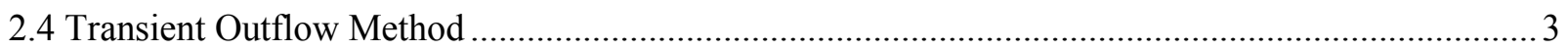

2.5 Determination of van Genuchten Parameters using Outflow Data ................................................5

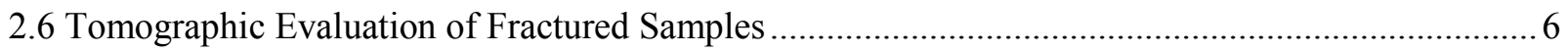

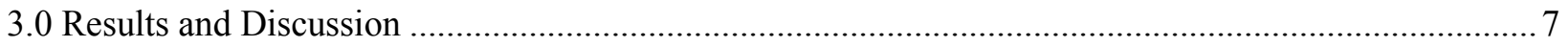

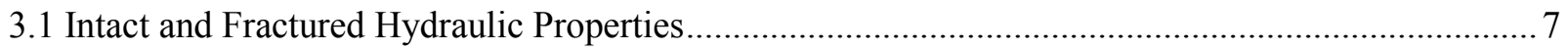

3.2 Tomographic Analysis of Fractured Saltstone Samples........................................................... 7

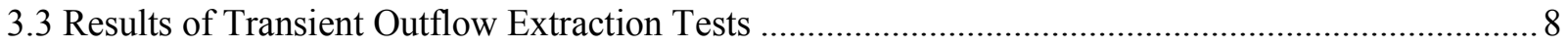

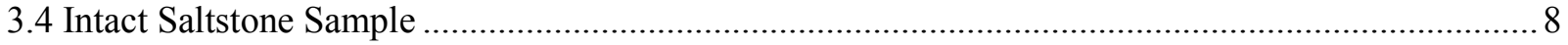

3.5 Saltstone Sample - Saw Cut Fully Penetrating Smooth Surface Fracture ..................................... 8

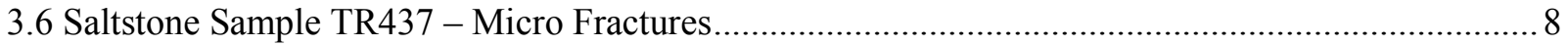

3.7 Saltstone Sample TR436- Micro Fractures and Fully Penetrating Rough Surface Fracture ............. 9

3.8 Comparison to FY2013 Special Analysis Assumptions.............................................................. 9

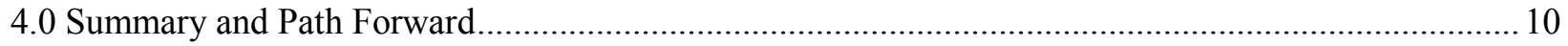

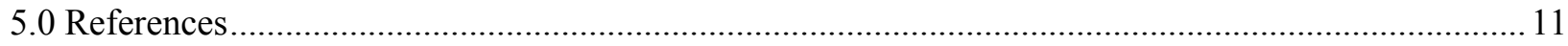

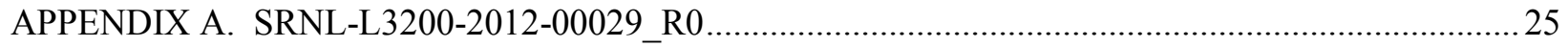

APPENDIX B. Saturated Hydraulic Conductivity Data Sheets ............................................................ 33 
SRNL-STI-2013-00522

Revision 0

\section{LIST OF TABLES}

Table 1. Hydraulic Properties of Fractured Saltstone Samples as Measured by SRNL ${ }^{1}$ .23

Table 2. Van Genuchten Parameters as Determined from Outflow Data using Hydrus ${ }^{\mathrm{a}}$ .23

Table 3. Comparison of Measured and Predicted Hydraulic Properties for TR436 and TR437. 23

\section{LIST OF FIGURES}

Figure 1. Fractured media properties viewed as a homogeneous blend of intact matrix and (a) fracture or (b) gravel surrogate properties (Flach 2011). 13

Figure 2. Unsaturated hydraulic conductivity for intact and degraded concrete based on matrix-fracture and matrix-gravel (fracture surrogate) blends (Flach 2011). 13

Figure 3. Intact Saltstone Sample C3 - Top View (a) and Bottom View (b). 14

Figure 4. Saltstone Sample C1 with Saw Cut Fully Penetrating Smooth Surface Fracture - Top View (a) and Bottom View (b). 14

Figure 5. Saltstone Sample TR437 with Micro Fracture Network - Top View (a) and Bottom View (b). 15

Figure 6. Saltstone Sample TR436 with Micro Fracture Network and Fully Penetrating Rough Surface

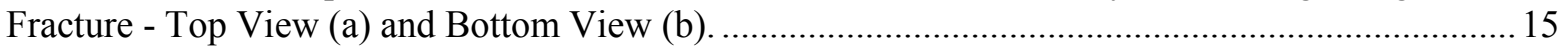

Figure 7. Flexible Wall Permeameter used for Saturated Hydraulic Conductivity Tests (ASTM D 5084).

Figure 8. Outflow Extractor, Fraction Collector, Peristaltic Pump, and High Precision Digital Balance used in Transient Outflow Extraction Tests. 16

Figure 9. Measured Outflow from Porous Ceramic Plate....................................................................... 17

Figure 10. Measured Outflow from Intact Saltstone Sample C3 ......................................................... 17

Figure 11. Measured Outflow from Saltstone Sample C1 with Saw Cut Fully Penetrating Smooth Surface Fracture. 18

Figure 12. Measured Outflow from Saltstone Sample TR437 with Micro Fractures Created by Oven Drying. .18

Figure 13. Relative Permeability Curves for Fractured and Intact Saltstone - TR437...... 19

Figure 14. Measured Outflow from Saltstone Sample TR436 with Micro Fractures Created by Oven Drying and with Fully Penetrating Rough Surface Fracture. 19

Figure 15. Relative Permeability Curves for Fractured and Intact Saltstone TR-436. 20 
Figure 16. Comparison of Unsaturated Hydraulic Conductivity for Samples TR436 and TR437 to Intact saltstone, Backfill Soil, and a 20\% Backfill (80\% intact saltstone) Blend.

Figure 17. Comparison of TR437 to a 10\% Sand and 90\% Intact Saltstone Blend as An Example of Improved Fit.

Figure 18. Longitudinal (a) and transverse (b) slice of sample TR437 showing micro-fracture network heterogeneity and large scale porosity as represented by black features $\left(\mathrm{K}_{\mathrm{s}}=1.42 \times 10^{-4} \mathrm{~cm} / \mathrm{sec}\right) \ldots . .22$

Figure 19. Longitudinal (a) and transverse (b) slice of sample TR436 showing micro-fracture network heterogeneity and large scale porosity as represented by black features $\left(\mathrm{K}_{\mathrm{s}}=1.99 \times 10^{-6} \mathrm{~cm} / \mathrm{sec}\right) \ldots . .22$ 


\section{LIST OF ABBREVIATIONS}

$\begin{array}{ll}\text { atm } & \text { atmosphere } \\ \text { CT } & \text { Computed Tomography } \\ \text { FWP } & \text { Flexible wall permeameter } \\ \text { FPM } & \text { Fractured porous media } \\ \text { MCC } & \text { Moisture Characteristic Curve } \\ \text { NRC } & \text { Nuclear Regulatory Commission } \\ \text { PA } & \text { Performance Assessment } \\ \text { psig } & \text { Pounds per square inch gauge } \\ \text { RAI } & \text { Request for Additional Information } \\ \text { SA } & \text { Special Analysis } \\ \text { SDF } & \text { Saltstone Disposal Facility } \\ \text { SRNL } & \text { Savannah River National Laboratory } \\ \text { SRS } & \text { Savannah River Site } \\ \text { SS } & \text { Stainless Steel } \\ \text { USDOE } & \text { United States Department of Energy }\end{array}$


SRNL-STI-2013-00522

Revision 0

\subsection{Task Description}

A common disposal pathway for low level liquid radioactive wastes is incorporation into cementitious waste forms (e.g. saltstone). Considerable effort has been undertaken in the development of numerical modeling techniques to predict fluid flow and contaminant transport within the large monoliths that result from this disposal method. The accuracy of these numerical models is inherently linked to the accuracy of the material property estimates that form the basis for the model. The saturated hydraulic conductivity of intact saltstone is typically on the order of $10^{-9} \mathrm{~cm} / \mathrm{sec}$ (Dixon et al., 2009). Through moisture retention testing, drainage properties have been established for intact saltstone that form the basis for estimating the unsaturated hydraulic conductivity function $[K(\theta)]$ (Dixon et al., 2009). Hydraulic properties based upon intact saltstone have been used in Performance Assessment (PA) modeling for the Saltstone Disposal Facility (SDF) for various scenarios and time periods. However, other modeling cases assume that saltstone becomes degraded over time through fracturing.

The hydraulic properties, primarily unsaturated hydraulic conductivity/permeability, of fractured saltstone and concrete have not been explicitly measured. Plausible, but unvalidated, theoretical model constructs (Figure 1) for unsaturated hydraulic conductivity (Figure 2) are currently used in PA modeling for cracked saltstone and concrete (Flach 2011). The Nuclear Regulatory Commission (NRC) has expressed concern about the lack of model support for these assumed Moisture Characteristic Curves (MCC) data, as noted in Requests for Additional Information (RAIs) PA-8 and SP-4 (Savannah River Remediation, LLC, 2011).

Preliminary method development previously conducted by Kohn et al. (2012) identified transient outflow extraction as the most promising method for characterizing the unsaturated properties of fractured porous media. As part of the preliminary evaluation, Kohn et al. (2012) considered several fractured media analogs and tested multiple configurations using an outflow extraction chamber and method implemented by Dixon (2011). The initial research conducted by Kohn et al. (2012) provided a proof of concept for using the transient outflow extraction method for measuring the hydraulic properties of fractured media and served as the starting point for this task. The transient outflow extraction method was originally developed for testing soil and sediment samples (Kool and Parker, 1988; Hopmans et al., 2002). While the technique is well established for soils, the applicability of the method to fractured cementitious material has not been established.

The objective of this task was to advance PA model support by developing an experimental method for determining the hydraulic conductivity of fractured cementitious materials under unsaturated conditions, and to demonstrate the technique on fractured saltstone samples. The task was requested through Task Technical Request (TTR) HLW-SSF-TTR-2012-0016 and conducted in accordance with Task Technical \& Quality Assurance Plan (TTQAP) SRNL-TR-2012-00090. 
SRNL-STI-2013-00522

Revision 0

\subsection{Methods}

The unsaturated hydraulic properties of four saltstone samples (1 intact and 3 fractured) were evaluated using a transient cumulative outflow method. Cumulative outflow data as a function of time and applied pressure were collected for each sample. These data were then used to optimize the van Genuchten parameters using an inverse solution to the Richards equation for flow in variably saturated media (Hopmans et al., 2002). Standard hydraulic properties were measured for each sample including saturated hydraulic conductivity and total porosity. Characteristic curves were developed for the fractured samples and compared to the curves used for intact saltstone.

\subsection{Sample Preparation}

A key component of the method development effort was the creation of fractured saltstone samples. Several methods for inducing fractures were identified and tested yielding mixed results. The methods tested were freezing, cracking with blunt force, shearing, cutting, and oven drying. Freezing was initially identified as a promising method of inducing fractures due to the expansion of water in the process of forming ice. To investigate this method, intact saltstone was placed in an ordinary freezer for several days $\left(\sim 0^{\circ} \mathrm{F}\right)$. After removal from the freezer, visual inspection revealed no observable fractures in the intact saltstone. This may be due to the high salt content of the simulant used to batch saltstone because salt lowers the freezing temperature of water. Flash freezing or exposure to dry ice may have improved the chances of inducing fracturing but this method was not pursued.

Cracking with blunt force was also considered as a method of inducing fractures. This method was tested on ordinary concrete samples and one tank grout sample with good success. A sharp blow from a sledge hammer sheared these samples longitudinally producing a rough surface fracture. However, due to its low compressive strength, the method was not useful for inducing fractures in saltstone. Application of a blunt force to saltstone simply crushed the sample into small pieces rendering it useless for testing purposes.

Shearing and cutting were tested on several saltstone samples. Cutting was attempted with a band saw and a miter saw with an abrasive blade. Cutting with the band saw produced an uneven fracture surface that was deemed unsuitable for testing. Cutting with the miter saw produced a smooth surface fracture that was deemed acceptable for further testing. Samples were also fractured by shearing much in the same manner that ceramic tile is sheared. The samples were scored and placed in a vice. An instantaneous shearing force was applied that resulted in a relatively clean break producing a rough surface fracture that was deemed suitable for testing.

The final method considered was oven drying. Samples were placed in an oven and maintained at a temperature of $105^{\circ} \mathrm{C}$ for several days. This method produced a network of fine microfractures that could be representative of actual degraded saltstone. Therefore, this method was identified as the most successful of those attempted.

\subsection{Sample Selection}

After testing various methods for inducing fractures, four sample types were ultimately selected for this task: 1) intact saltstone, 2) intact saltstone with a single saw cut, smooth surface fracture, 3) micro-fractured saltstone (induced by oven drying), and 4) micro-fractured saltstone with a single fully penetrating rough surface fracture. 
An excess saltstone mold sample from a previous task was the source of sample types 1 and 2 . The sample had been cured and stored in the mold at ambient room conditions prior to selection for this task. Upon receipt of the sample, it was removed from the mold and cut into several pieces of varying lengths for testing purposes. Each section of sample was labeled and photographed for reference. The intact saltstone sample was labeled C3 and is shown in Figure 3. Sample type 2 was cut longitudinally using a miter saw with an abrasive blade. This resulted in a single, fully penetrating smooth surfaced fracture. The sample was labeled $\mathrm{Cl}$ and is shown in Figure 4.

Sample type 3 was an excess sample from a previous task that had been oven dried to determine bulk material properties. The sample was previously labeled TR437 and is shown in Figure 5. This sample was chosen because the intact properties of the sample are known (Dixon et al., 2008) and it exhibits the desired micro-fracture network created during the drying process. The fracture network can be seen in Figure 5. The fourth sample type tested was also an excess sample from the same project as TR437 and was labeled TR436. Both samples came from the same batch of wet saltstone and were intended to be nearly identical in terms of hydraulic and physical properties (Dixon et al., 2008). TR436 was also oven dried to determine bulk material properties as part of the earlier task and exhibits a micro fracture network similar to TR437. A single, fully penetrating, rough surface fracture was also created in TR436 by the instantaneous application of a blunt shearing force. The micro fracture network and the single, fully penetrating, rough surface fracture present in TR436 are shown in Figure 6.

The physical dimensions of each sample were measured with a caliper and recorded to facilitate bulk material property calculations. Prior to testing and during storage, each sample was maintained under vacuum saturation in de-aired water.

\subsection{Saturated Hydraulic Properties}

Each sample type was tested for saturated hydraulic conductivity following method ASTM D 5084-03 using a flexible wall permeameter (Figure 7). ASTM Method 5084-03 is used for measuring the saturated hydraulic conductivity $(K)$ of porous materials with hydraulic conductivities ranging from $1 \mathrm{E}-03$ to $1 \mathrm{E}-09 \mathrm{~cm} / \mathrm{sec}$. A falling head/rising tail apparatus was chosen to measure the hydraulic conductivity of the saltstone samples used in this task. The increased resolution in data collected using the falling head/rising tail apparatus justifies the additional equipment complexity when testing low $K$ materials.

The porosity and dry bulk density of each sample type was determined after completion of the outflow extraction testing. To determine porosity and dry bulk density, the samples were oven dried at $105^{\circ} \mathrm{C}$ following all testing. The oven dried mass of each sample was corrected for salt precipitation using the method presented by Dixon et al. (2009).

\subsection{Transient Outflow Method}

Preliminary method development previously conducted by Kohn et al. (2012) identified transient outflow extraction as the most promising method for characterizing the unsaturated properties of fractured porous media. As part of the preliminary evaluation, Kohn et al. (2012) considered several fractured media analogs and tested multiple configurations using an outflow extraction chamber and method implemented by Dixon (2011). The research conducted by Kohn et al. (2012) provided a proof of concept for using the transient outflow extraction method for measuring the hydraulic properties of fractured media and served as the starting point for this task. The transient outflow extraction method was originally developed for testing soil and sediment samples (Kool and Parker, 1988; Hopmans et al., 2002). Although well established for soils, 
considerable modifications and improvements were necessary to adapt the method for use on fractured cementitious materials.

The more significant improvements to the outflow extraction method included:

- The use of a high precision digital balance for logging outflow mass.

- The use of a high precision, low range pressure gauge.

- The use of a high flow, low air entry pressure porous ceramic plate in the outflow extractor.

- Using a low volume effluent line connecting the outflow extractor to the digital balance. This produced a consistent drop mass and reduced evaporative effects.

- The use of rectangular cross-section O-rings for sealing the extraction chamber.

- The use of multiple inline high precision regulators connected in series to a bank of four compressed gas cylinders. This allowed for precise application of pressure during each test.

Transient outflow experiments were carried out on four sample types: 1) intact saltstone, 2) intact saltstone with a single saw cut, smooth surface fracture, 3 ) micro-fractured saltstone (induced by oven drying), and 4) micro-fractured saltstone with a single fully penetrating rough surface fracture. Each sample type was initially tested for saturated hydraulic conductivity as described in Section 2.2. Following testing for saturated hydraulic conductivity, samples were vacuum saturated for several days in de-aired water. The saturated mass of each sample was determined using a high precision balance immediately prior to the start of outflow extraction testing.

The outflow extraction system consists of the outflow extractor, a peristaltic pump, and a high precision balance to monitor effluent from the extractor (Figure 8). The outflow extractor contains a porous ceramic that provides the interface between the applied pressure inside the extractor and ambient atmospheric pressure outside the extractor. The sample rests inside the extractor on the surface of the porous ceramic plate. For the purposes of this testing, a high flow porous ceramic plate with an air entry pressure of $1000 \mathrm{~cm} \mathrm{H}_{2} \mathrm{O}$ was selected. The saturated hydraulic conductivity of the plate is reported by the manufacturer (Soil Moisture, Inc.) to be $8.6 \mathrm{E}-06 \mathrm{~cm} / \mathrm{sec}$. Prior to the start of each test, the plate was saturated with de-aired water. This was accomplished by pressurizing a known mass of de-aired water in the chamber. This allowed the de-aired water to flow through the plate until the chamber was empty thereby saturating the plate. Care was taken not to exceed the air entry pressure of the plate during this process. Outflow was monitored on the digital balance to determine when the bulk of the water had been pushed through the plate.

The outflow extractor consists of a single inlet port for pressure application. The outlet side of the extractor consists of two ports, one which is used to drain effluent from the sample and a secondary port that is used to remove air from beneath the ceramic plate prior to testing. Using an arrangement of valves, the two outlet ports, and a peristaltic pump, de-aired water was circulated beneath the ceramic plate to remove entrapped air. Once this process was completed, a valve was used to close the secondary outlet port. Small diameter tubing was connected to the primary outlet port. The end of this tubing was maintained at a height equal to the bottom of the sample. Outflow experiments were carried out by pressurizing the extractor using compressed air. Several pressure increments were used in each transient test ranging from about 5 to $800 \mathrm{~cm}_{2} \mathrm{O}$. These pressures were maintained using a series of high precision multistage gas regulators. Effluent from each sample was monitored using a digital balance and logged directly to a computer every five seconds. Ultimately, the balance served as a drop counter and the mass of each drop of water was converted to volume using a density of $1.00 \mathrm{~g} / \mathrm{cm}^{3}$. 
Cumulative outflow was converted to cumulative flux by dividing the volume of effluent by the total area of the sample. The cumulative flux dataset was the input into the Hydrus-1D model.

Following each outflow test, the sample was removed from the ceramic plate and oven dried at $105^{\circ} \mathrm{C}$. Porosity and dry bulk density were determined for each sample following standard geotechnical methods.

\subsection{Determination of van Genuchten Parameters using Outflow Data}

It is standard practice to use theoretical methods to predict the unsaturated hydraulic conductivity based upon measured moisture retention data and outflow extraction data. These methods are generally based on pore-size distribution models, and have been shown to perform reasonably well for coarse textured soils and other porous media having relatively narrow pore-size distributions (USDA, 1998). One of the objectives of this task is to evaluate the applicability of these models to fractured cementitious media.

The closed form analytical expression developed by van Genuchten which predicts moisture content as a function of pressure was used for this analysis. The relationship is given as:

$$
\begin{gathered}
\theta(h)=\theta_{r}+\frac{\theta_{s}-\theta_{r}}{\left[1+(\alpha h)^{n}\right]^{m}} \quad h \leq 0 \\
\theta(h)=\theta_{s} \quad h>0
\end{gathered}
$$

where $\theta(h)$ is moisture content at the pressure head $h, \theta_{\mathrm{r}}$ is residual moisture content, $\theta_{\mathrm{s}}$ is the saturated moisture content, $h$ is pressure head, $\alpha$ is a constant related to the inverse of the airentry pressure, and $n$ is a measure of the pore-size distribution. The constraint $m=1-1 / n$ was used as suggested by van Genuchten (van Genuchten, 1980; van Genuchten et al., 1991).

The van Genuchten curve fitting parameters $\alpha, n, \mathrm{~m}, \theta_{\mathrm{s}}$, and $\theta_{\mathrm{r}}$ were optimized by numerical inversion using the computer program Hydrus-1D based upon measured outflow data from each of the sample types (Šimůnek et al., 2008). Using Hydrus-1D, a simple one-dimensional flow model consisting of two layers was created to represent the sample and porous ceramic plate. Properties of the ceramic plate $\left(1000 \mathrm{~cm} \mathrm{H}_{2} \mathrm{O}\right.$, high flow $)$ were provided by the vendor $\left(\mathrm{K}_{\mathrm{s}}=\right.$ $8.60 \mathrm{E}-06 \mathrm{~cm} / \mathrm{sec})$. In order to be certain that the ceramic plate stayed saturated during model simulations, a high air entry value was used for the ceramic plate $(\alpha=1.0 \mathrm{E}-20)$.

For each sample type, initial estimates of $\alpha, \eta, m, \theta_{\mathrm{s}}$, and $\theta_{\mathrm{r}}$ based on measured physical properties and test data were input into Hydrus-1D. Then, using a parameter optimization technique, Hydrus-1D fitted Richards' equation to the measured outflow data. The form of Richards' equation used in Hydrus-1D is given by:

$$
\frac{\partial \theta}{\partial x}=\frac{\partial}{\partial x}\left[K(h)\left(\frac{\partial h}{\partial x}\right)+1\right]
$$


Hydrus-1D was used to optimize the van Genuchten parameters and to estimate saturated hydraulic conductivity.

The curve fitting parameters $\left(\alpha, \eta, \mathrm{m}, \theta_{\mathrm{s}}\right.$, and $\left.\theta_{\mathrm{r}}\right)$ from Hydrus-1D were used to calculate the effective saturation (or reduced water content), $S_{e}$, at incremental pressure heads according to

$$
S_{e}=\frac{S-S_{r}}{1-S_{r}}=\frac{1}{\left[1+(\alpha h)^{n}\right]^{m}}
$$

where $S_{r}$ denotes residual saturation. Using $S_{e}$, the relative hydraulic conductivity was calculated at incremental pressure heads using the Mualem-van Genuchten type function

$$
K=S_{e}^{L}\left[1-\left(1-S_{e}^{1 / m}\right)^{m}\right]^{2}
$$

where $L$ is an empirical pore-connectivity parameter and assumed to be 0.5 (van Genuchten et al., 1991).

Saturation $(S)$ was calculated at various pressure heads according to

$$
S=S_{r}+\left(\frac{1-S_{r}}{\left[1+(\alpha h)^{n}\right]^{m}}\right)
$$

where residual saturation, $S_{r}$, is equal to $\theta_{r} / \theta_{s}$ (the residual moisture content divided by the saturated moisture content).

\subsection{Tomographic Evaluation of Fractured Samples}

Computed tomographic (CT) imaging was performed on two of the fractured saltstone samples, TR436 and TR437. A $420 \mathrm{keV}$ x-ray tube was used to acquire the raw projection images. The detector used was a $1.5 \mathrm{~K} \times 1 \mathrm{~K}$ pixel Photometrics charge-coupled device (CCD) camera with an $85 \mathrm{~mm}$ lens viewing an image quality indicator (IQI) glass scintillator. The scintillator converts x-ray energy into visible light which can be imaged with light sensitive detectors.

Samples were placed on a rotational turntable controlled by data acquisition software. The samples were imaged at 0.5 degree increments in the rotational angle for a total of 760 projection images. The raw projection data was processed by subtracting the dark current signal then taking the log of the ratio of the sample image to the un-attenuated beam. This transforms the data into the x-ray attenuation space. The projections were then Fourier transformed and filtered in the frequency domain to produce filtered projections. The filtered projections were then back projected through the object space using a cone beam reconstruction algorithm to provide reconstructed planes perpendicular to the axis of rotation and the raw projection coordinates. The set of reconstructed planes constitutes a 3-D data set which represents the attenuation coefficients of the sample. This 3-D data set was then sliced and viewed from different angles. For ease of viewing, movie files were created showing a sequence of images that are planes perpendicular to the axis of rotation or planes that are parallel to the axis of rotation. From these movies, still images were captured to show the internal characteristics of the fractured samples. 
SRNL-STI-2013-00522

Revision 0

\subsection{Results and Discussion}

The results presented in this report document the method development process associated with using the transient outflow extraction method for determining the unsaturated hydraulic properties of fractured saltstone. Four sample types were tested with differing fracture geometries. Of the four sample types tested, two yielded datasets suitable for analysis with the Hydrus-1D code. The Hydrus-1D code was used to generate van Genuchten curve fitting parameters for the two datasets. Using these curve fitting parameters, hydraulic characteristic curves were developed and compared to previously report characteristic curves for intact saltstone.

\subsection{Intact and Fractured Hydraulic Properties}

The saturated hydraulic conductivity of each sample type was determined using a flexible wall permeameter following the methods outline in Section 2.3. The results of this testing are presented in Table 1 and Appendix B. Samples with the ID "Salt-C\#" were all cut from the same mold sample and are presumed to have identical intact hydraulic properties. The sample used for saturated hydraulic conductivity testing was labeled "Salt-C4". The saturated hydraulic conductivity of this sample was determined to be $<1 \mathrm{E}-09 \mathrm{~cm} / \mathrm{sec}$ which is the lower limit of detection for the flexible wall permeameter as discussed in method ASTM D 5084-03. The intact saturated hydraulic conductivity of samples Salt-C1 and Salt-C3 were assumed to be identical as shown in Table 1.

Sample Salt-C1 was saw-cut to produce a fully penetrating smooth surface fracture. The fractured conductivity of this sample was determined to be $8.8 \mathrm{E}-05 \mathrm{~cm} / \mathrm{sec}$, which is almost four orders of magnitude greater than the intact conductivity. Sample Salt-C3 was scored and sheared to produce a fully penetrating rough surface fracture. The fractured conductivity of this sample was determined to be $5.6 \mathrm{E}-06 \mathrm{~cm} / \mathrm{sec}$, which is about three orders of magnitude greater than the intact conductivity.

For samples TR436 and TR437, intact hydraulic properties were previously reported by Dixon et al. (2008). The saturated hydraulic conductivities of TR436 and TR437 were reported as 5.0E-09 and $1.1 \mathrm{E}-09 \mathrm{~cm} / \mathrm{sec}$, respectively. TR436 (micro-fractures with fully penetrating rough surface fracture) had a fractured conductivity of $2.0 \mathrm{E}-05 \mathrm{~cm} / \mathrm{sec}$. TR437 (micro-fractures only) had a fractured conductivity of $1.4 \mathrm{E}-04 \mathrm{~cm} / \mathrm{sec}$. For both TR436 and TR437, fracturing resulted in a remarkable increase in hydraulic conductivity (three to four orders of magnitude for both samples).

Porosity and dry bulk density results are also presented in Table 1. For the single fracture samples (Salt-C1 and Salt-C3), fractured dry bulk density and porosity were not measured as it was desired to preserve these samples for possible future testing. It is assumed the porosity and dry bulk density of these samples would be similar to the intact values because the single fracture represents a small volume compared to the total volume of the sample. For samples TR436 and TR437, it is noted that the fractured dry bulk density was lower and the porosity was higher compared to the intact measurements.

\subsection{Tomographic Analysis of Fractured Saltstone Samples}

CT scans were performed on samples TR436 and TR437 to help qualify the extent of the microfracture network visually observed in each sample. Tomographic reconstructions perpendicular and longitudinal to the cylindrical axis were used to provide cross sectional and transverse views. 
These scans were prepared to show pores, fractures, voids, aggregate, and the cementitious matrix as well as other internal features in both samples. The images are shown in Figure 18 and Figure 19.

\subsection{Results of Transient Outflow Extraction Tests}

In order to test the integrity of the outflow extraction system and to verify that any measured outflow was the result of fracture drainage rather than drainage from the outflow apparatus, a test was conducted with no sample in the chamber. The ceramic plate was saturated with de-aired water and various pressure increments were applied over the course of the test. The results of this test are presented in Figure 9. A single drop $(<0.03 \mathrm{~g})$ was observed about two hours into the 40 hour test and is most likely attributable to the ceramic plate being slightly oversaturated.

\subsection{Intact Saltstone Sample}

Intact sample Salt-C3 was tested in the outflow extractor for almost 80 hours up to a pressure of about $800 \mathrm{~cm} \mathrm{H}_{2} \mathrm{O}$ (Figure 10). No measureable outflow was observed from this intact sample. This was expected because the estimated air entry pressure for saturated intact saltstone has been estimated to be in excess of $100,000 \mathrm{~cm} \mathrm{H}_{2} \mathrm{O}\left(\alpha=1 \mathrm{E}-05 \mathrm{~cm}^{-1}\right)$. Based on the results from sample Salt-C3, it is reasonable to assume that any measured outflow from other fractured samples is the result of fracture drainage and not drainage of the bulk saltstone matrix. Because there was no outflow observed over the course of the test, analysis with Hydrus-1D was not possible.

\subsection{Saltstone Sample - Saw Cut Fully Penetrating Smooth Surface Fracture}

Sample Salt-C1 was saw-cut to produce a fully penetrating smooth surface fracture. The sample was reassembled and held together with tape for testing purposes. The results from the test are presented in Figure 11. The smooth faced fracture completely drained with a pressure application of only $5 \mathrm{~cm} \mathrm{H}_{2} \mathrm{O}$. The total volume of effluent expelled from the fracture was $1.80 \mathrm{ml}$. Due to the complete drainage of the smooth faced fracture at the first applied pressure increment, it was decided that analysis of the dataset with Hydrus-1D would not be worthwhile. Better parameter optimization has been reported when drainage occurs over multiple transient pressure increments with non-unique solutions being a problem associated with one step outflow datasets (Eching and Hopmans, 1993).

\subsection{Saltstone Sample TR437 - Micro Fractures}

Sample TR437 (with micro-fractures) was tested at various pressure increments for over 140 hours. The results of the test are shown in Figure 12. A total volume of $1.64 \mathrm{ml}$ was extracted from the sample over the duration of the test. Hydrus-1D was used to analyze the dataset from TR437. Although Hydrus-1D is capable of optimizing all of the van Genuchten curve fitting parameters as part of the inverse solution process, it is prudent to constrain the model to measured properties when possible to improve the fit to the measured data and minimize or eliminate numerical instability. As such, the initial simulations of the TR437 dataset were constrained by the measured porosity $\left(\theta_{\mathrm{s}}\right)$ and saturated hydraulic conductivity $\left(\mathrm{K}_{\mathrm{s}}\right)$. Hydrus-1D was allowed to optimize the other curve fitting parameters $\theta_{\mathrm{r}}, \alpha, \eta$, and $\mathrm{m}$. However, due to numerical instability, it was not possible to obtain a reasonable fit of the measured data with the model constrained by both the measured porosity and saturated hydraulic conductivity. The best fit $\left(\mathrm{r}^{2}=0.95\right)$ was obtained when Hydrus-1D was constrained only by the measured porosity with all other parameters optimized. In general, good agreement is noted between the measured and predicted outflow data (Figure 12). The optimized curve fitting parameters and predicted conductivity values are presented in Table 2. A comparison of the measured and predicted hydraulic conductivity is presented in Table 3. The predicted hydraulic conductivity for TR437 was about an order of magnitude higher than the measured value. One possible explanation for this 
difference is the lateral confining pressure applied to the sample during testing with the flexible wall permeameter. The confining pressure may tend to compress and reduce the aperture of fractures that otherwise are unaffected during outflow testing. The other optimized parameters seemed reasonable for fractured media. The predicted air entry pressure was approximately 22 $\mathrm{cm} \mathrm{H}_{2} \mathrm{O}$ which is in good agreement with the observed test data. This contrasts sharply with the predicted air entry pressure for intact saltstone $\left(100,000 \mathrm{~cm} \mathrm{H}_{2} \mathrm{O}\right)$. The predicted residual moisture content $\left(\theta_{\mathrm{r}}\right)$ was approximately 0.42 which implies that the majority of the moisture was retained in the bulk matrix. This is expected based on the reported drainage properties of intact saltstone (Dixon et al., 2009).

Figure 13 compares the relative permeability curve for intact saltstone (Dixon et al., 2009) to the relative permeability curve for sample TR437. The contrast noted between the curves is expected due to the drainage properties observed in the fractured sample.

\subsection{Saltstone Sample TR436- Micro Fractures and Fully Penetrating Rough Surface Fracture}

Sample TR436 (with micro-fractures and fully penetrating rough surface fracture) was tested at various pressure increments for over 160 hours. The results of the test are shown in Figure 14. A total volume of $1.74 \mathrm{ml}$ was extracted from the sample over the duration of the test. Hydrus-1D was used to analyze the dataset from TR436. As with sample TR437, Hydrus-1D was initially constrained by the measured porosity and saturated hydraulic conductivity. Unlike with TR437, a reasonable fit to the measured data was obtained using this approach $\left(r^{2}=0.98\right.$, Figure 14). However, the optimized value of $\theta_{\mathrm{r}}(0.11)$ seems too low for saltstone (Table 2) for reasons previously discussed. Therefore, Hydrus-1D was allowed to optimize hydraulic conductivity and a more reasonable value of $\theta_{\mathrm{r}}(0.39)$ was obtained. The predicted air entry pressure was about 80 $\mathrm{cm} \mathrm{H}_{2} \mathrm{O}$ which is reasonable for fractured media but is somewhat higher than would be expected based on the observed outflow data. Both Figure 12 and Figure 14 show that Hydrus-1D had difficulty matching the measured outflow at low applied pressures.

Figure 15 compares the relative permeability curve for intact saltstone (Dixon et al., 2009) to the relative permeability curves for sample TR436. The contrast noted between the curves is expected due to the drainage properties observed in the fractured sample.

\subsection{Comparison to FY2013 Special Analysis Assumptions}

The FY2013 Special Analysis (SA) for Saltstone Disposal Units 1, 2, and 4 models physicallydegraded saltstone as a blend of intact saltstone and backfill soil (Jordan and Flach 2013, Section 2.1). Fully degraded saltstone is assumed to behave as backfill ( $100 \%$ blend). Partial degradation corresponds to intermediate blends between 0 and 100\%. Figure 16 compares unsaturated hydraulic conductivity for samples TR436 and TR437 to intact saltstone, backfill soil, and a 20\% backfill ( $80 \%$ intact saltstone) blend. Both samples exhibit significant physical degradation as evidenced by saturated conductivities that are three to four orders of magnitude larger than the SA value for intact saltstone. The measured hydraulic conductivity function for TR436 is well matched by a blend of $20 \%$ backfill and $80 \%$ intact saltstone. TR437 is better represented by $100 \%$ backfill soil. For the TR437 sample, the surrogate soil curve undershoots the saturated conductivity and overshoots unsaturated conductivities in the 10-1000 cm range. A somewhat better fit can be achieved by blending intact saltstone with a coarser-grained soil such as sand. Figure 17 compares TR437 to a 10\% sand and $90 \%$ intact saltstone blend as an example of 
improved fit. These comparisons indicate that soil-saltstone blends can serve as reasonable surrogates for saltstone degraded in the manner of samples TR436 and TR437.

\subsection{Summary and Path Forward}

The purpose of this task was to develop a method for determining the hydraulic conductivity of fractured cementitious materials under unsaturated conditions, and apply the technique to fractured saltstone samples.

Preliminary method development previously conducted by Kohn et al. (2012) identified transient outflow extraction as the most promising method for characterizing the unsaturated properties of fractured porous media. As part of the preliminary evaluation, Kohn et al. (2012) considered several fractured media analogs and tested multiple configurations using an outflow extraction chamber and method implemented by Dixon (2011). The research conducted by Kohn et al. (2012) provided a proof of concept for using the transient outflow extraction method for measuring the hydraulic properties of fractured media and served as the starting point for this task. The transient outflow extraction method was originally developed for testing soil and sediment samples (Kool and Parker, 1988; Hopmans et al., 2002). Considerable modifications and improvements were necessary to adapt the method for use on fractured cementitious materials. The more significant improvements included the use of a high precision digital balance for logging outflow mass, the use of a high flow, low air entry pressure porous ceramic plate in the outflow extractor, a low volume effluent line connecting the outflow extractor to the digital balance, and the use of rectangular cross-section O-rings for sealing the extraction chamber.

While the research conducted by Kohn et al. (2012) focused on fractured media analogs such as stacked glass slides, the current task focused directly on fractured saltstone. For the this task, four sample types with differing fracture geometries were considered: 1) intact saltstone, 2) intact saltstone with a single saw cut, smooth surface fracture, 3) micro-fractured saltstone (induced by oven drying), and 4) micro-fractured saltstone with a single fully penetrating rough surface fracture.

Each sample type was tested initially for saturated hydraulic conductivity following method ASTM D 5084 using a flexible wall permeameter. Samples were subsequently tested using the transient outflow extraction method to determine cumulative outflow as a function of time and applied pressure. Of the four sample types tested, two yielded datasets suitable for analysis (sample types 3 and 4). The intact saltstone sample (sample type 1) did not yield any measureable outflow over the pressure range of the outflow test $\left(0-1000 \mathrm{~cm} \mathrm{H}_{2} \mathrm{O}\right)$. This was expected because the estimated air entry pressure for intact saltstone is on the order of 100,000 $\mathrm{cm} \mathrm{H}_{2} \mathrm{O}$ (Dixon et al., 2009). The intact saltstone sample with a single saw cut smooth surface fracture (sample type 2) did not produce useable data because the fracture completely drained at less than $10 \mathrm{~cm} \mathrm{H}_{2} \mathrm{O}$ applied pressure.

The cumulative outflow data from sample types 3 and 4 were analyzed using an inverse solution of the Richard's equation for water flow in variably saturated porous media. This technique was implemented using the computer code Hydrus-1D (Šimůnek et al., 2008) and the resulting output included the van Genuchten-Mualem water retention and relative permeability functions and predicted saturated hydraulic conductivity (Van Genuchten, 1980; Van Genuchten et al., 1991). Estimations of relative permeability and saturated conductivity are possible because the transient response of the sample to pressure changes is recorded during the multi-step outflow extraction test. Characteristic curves were developed for sample types 3 and 4 based on the results of the 
transient outflow method and compared to that of intact saltstone previously reported by Dixon et al. (2009).

The overall results of this study indicate that the outflow extraction method is suitable for measuring the hydraulic properties of micro-fractured porous media. The resulting cumulative outflow data can be analyzed using the computer code Hydrus-1D to generate the van Genuchten curve fitting parameters that adequately describe fracture drainage. The resulting characteristic curves are consistent with blended characteristic curves that combine the behaviors of low pressure drainage associated with fracture flow with high pressure drainage from the bulk saltstone matrix.

\subsection{References}

ASTM D 5084-03. Standard Test Methods for Measurement of Hydraulic Conductivity of Saturated Porous Materials Using a Flexible Wall Permeameter. ASTM International, West Conshohocken, PA.

Dixon, K. L. Estimating Hydraulic Properties For E-Area Sediments Using A Multi-Step Outflow Extraction Method. SRNL-STI-2010-00655, Rev. 0. February 2011.

Dixon, K. L., J. R. Harbour, and M. A. Phifer. 2009 Hydraulic and Physical Properties of ARP/MCU Saltstone Grout. SRNL-STI-2009-00419, Rev. 0.

Dixon, K. L., J. R. Harbour, and M. A. Phifer. 2008 Hydraulic and Physical Properties of Saltstone Grouts and Vault Concretes. SRNL-STI-2008-00421, Rev. 0.

Eching, S. O. and J. W. Hopmans. 1993. Optimization of Hydraulic Functions from Transient Outflow and Soil Water Pressure Data. Soil Science Society of America Journal, v57, n5, 1167 1175 .

Jordan, J. M. and G. P. Flach. 2013. Porflow Modeling Supporting the FY13 Saltstone Special Analysis. SRNL-STI-2013-00280, Rev. 0.

Flach, G. P., R. L. Nichols, and K. L. Dixon. Task Technical and Quality Assurance Plan for Determining the Unsaturated Permeability of Fractured Saltstone. SRNL-TR-2012-00090, Rev. 0. May 2012.

Flach, G. P. Hydraulic Properties of Degraded Cementitious Materials in Performance Assessments. SRNL-L4321-2011-00006. April 28, 2011.

Hopmans, J. W., J. Šimůnek, N. Romano, and W. Durner, Inverse Modeling of Transient Water Flow, In: Methods of Soil Analysis, Part 1, Physical Methods, Chapter 3.6.2, Eds. J. H. Dane and G. C. Topp, Third edition, SSSA, Madison, WI, 963-1008, 2002.

Jordan, J. M., and G. P. Flach. PORFLOW Modeling Supporting the FY13 Saltstone Special Analysis. SRNL-STI-2013-00280, Rev. 0. May 2013.

Kool, J. B. and J. C. Parker. 1988. Analysis of the Inverse Problem for Transient Unsaturated Flow. Water Resources Research, v24, n6, 817-830. 
Kohn, J. L., K. L. Dixon, and R. L. Nichols. 2011. Fractured media update. SRNL-L3200-201200029_R0.

Mualem, Y. 1976. A New Model for Predicting the Hydraulic Conductivity of Unsaturated Porous Media. Water Resources Research, v12, n3, 513-522.

Or, D. and M. Tuller. Flow in Unsaturated Porous Media: Hydraulic Conductivity of Rough Surfaces. Water Resources Research, v36, n5, 1165-1177.

Task Technical Request HLW-SSF-TTR-2012-0016, Rev. 1. Measure the Unsaturated Permeability of Fractured Saltstone. May 10, 2012.

Savannah River Remediation LLC. Comment Response Matrix for Nuclear Regulatory Commission RAI-2009-02 Second Request for Additional Information (RAI) on the Saltstone Disposal Facility Performance Assessment (SRR-CWDA-2009-00017, Revision 0, dated October 29, 2009). SRR-CWDA-2011-00044 Rev. 1.

Šimůnek, J., M. Th. van Genuchten, and M. Sejna. 2008. The Hydrus-1D Software Package for Simulating the One-Dimensional Movement of Water, Heat, and Multiple Solutes in VariablySaturated Media, Version 4.14. Department of Environmental Sciences, University of CaliforniaRiverside, Riverside, CA, 92521.

van Genuchten, M. Th., 1980, A Closed-form Equation for Predicting the Hydraulic Conductivity of Unsaturated Soils, Soil Science Society of America Journal, v44, 892-898.

van Genuchten, M. Th., F. J. Leij, and S. R. Yates, 1991, The RETC Code for Qualifying the Hydraulic Functions of Unsaturated Soils, Version 1.0, EPA Report 600/2-91/065, U.S. Salinity Laboratory, USDA, ARS, Riverside, California. 
fractured matrix

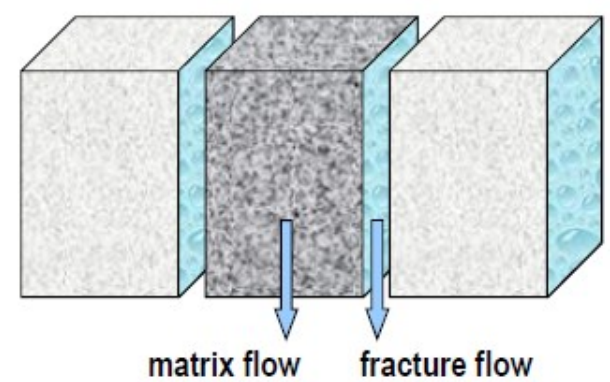

(a) vs. gravel-matrix blend

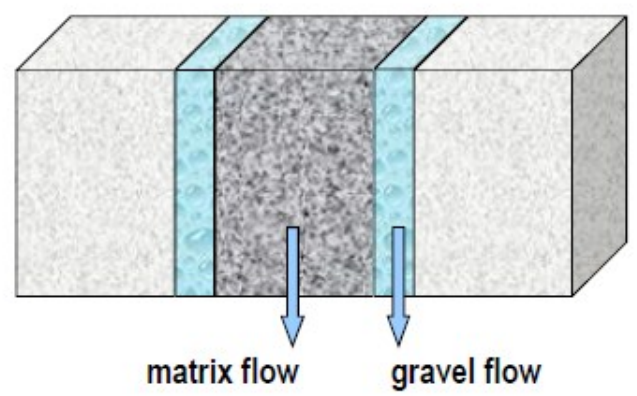

(b)

Figure 1. Fractured media properties viewed as a homogeneous blend of intact matrix and (a) fracture or (b) gravel surrogate properties (Flach 2011).

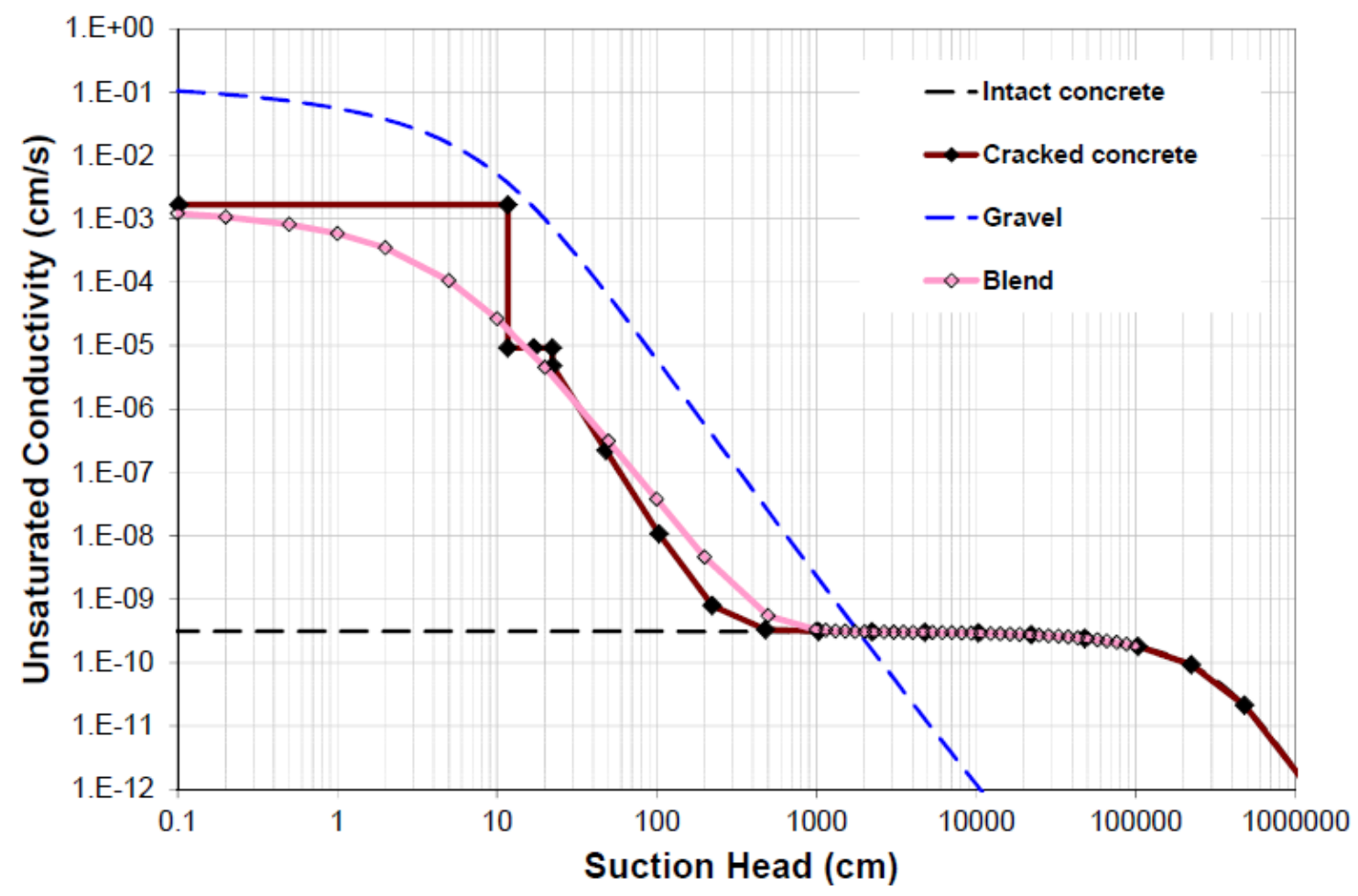

Figure 2. Unsaturated hydraulic conductivity for intact and degraded concrete based on matrix-fracture and matrix-gravel (fracture surrogate) blends (Flach 2011). 

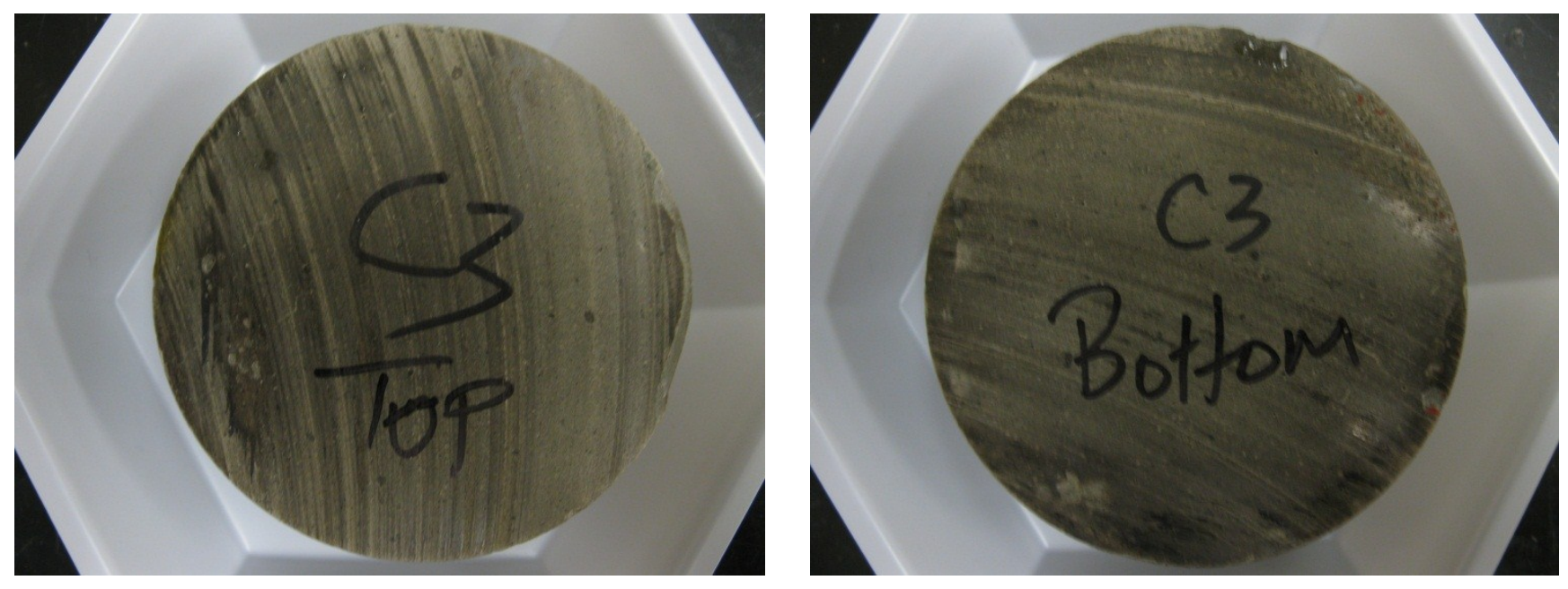

(a)

(b)

Figure 3. Intact Saltstone Sample C3 - Top View (a) and Bottom View (b).
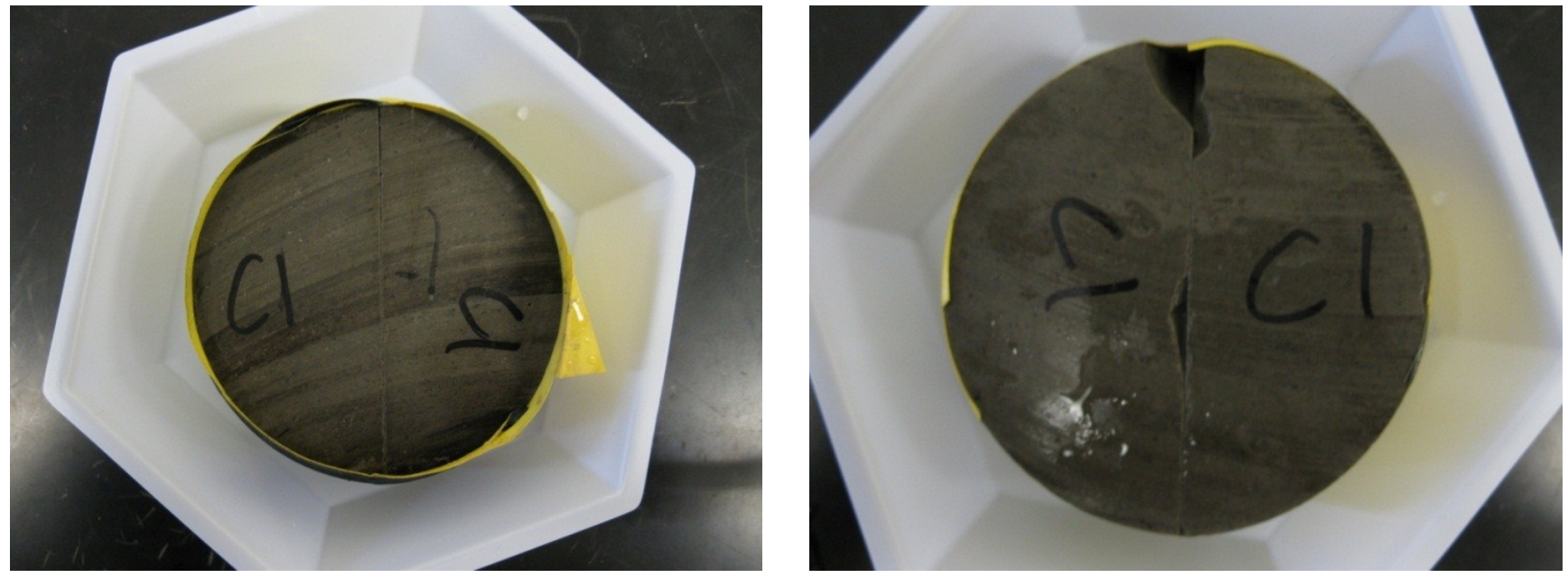

(a)

(b)

Figure 4. Saltstone Sample C1 with Saw Cut Fully Penetrating Smooth Surface Fracture Top View (a) and Bottom View (b). 

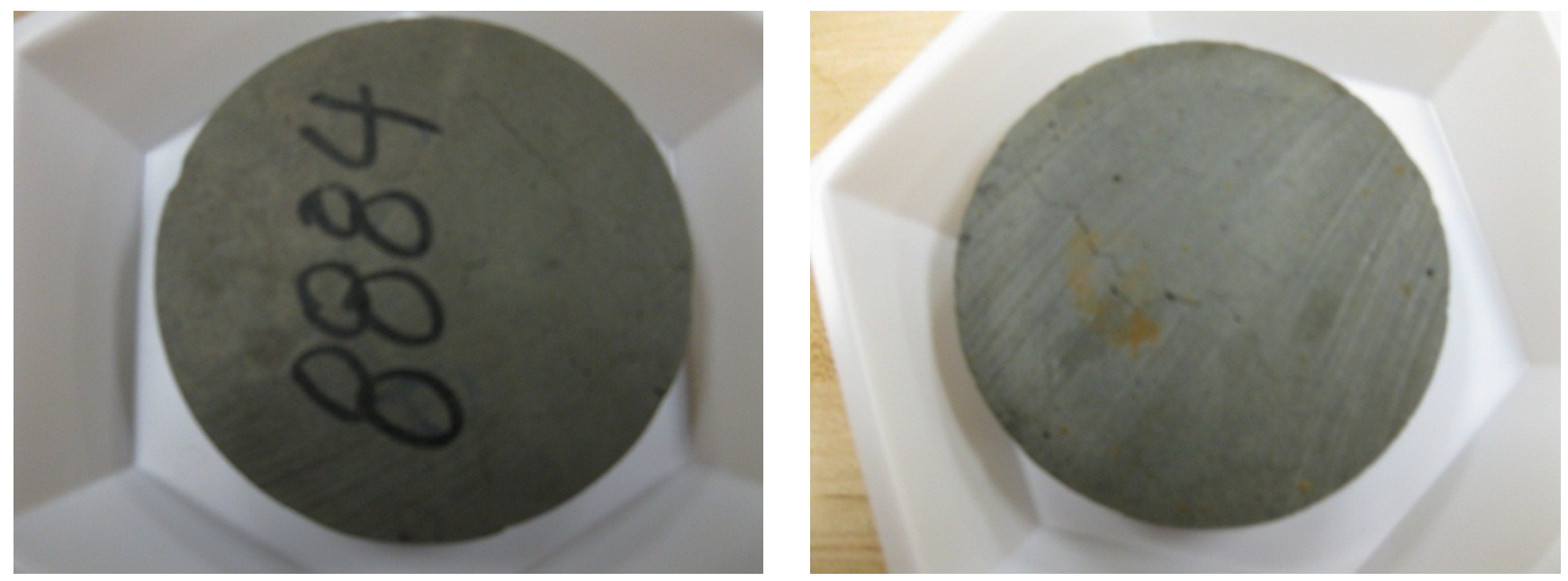

(a)

(b)

Figure 5. Saltstone Sample TR437 with Micro Fracture Network - Top View (a) and Bottom View (b).
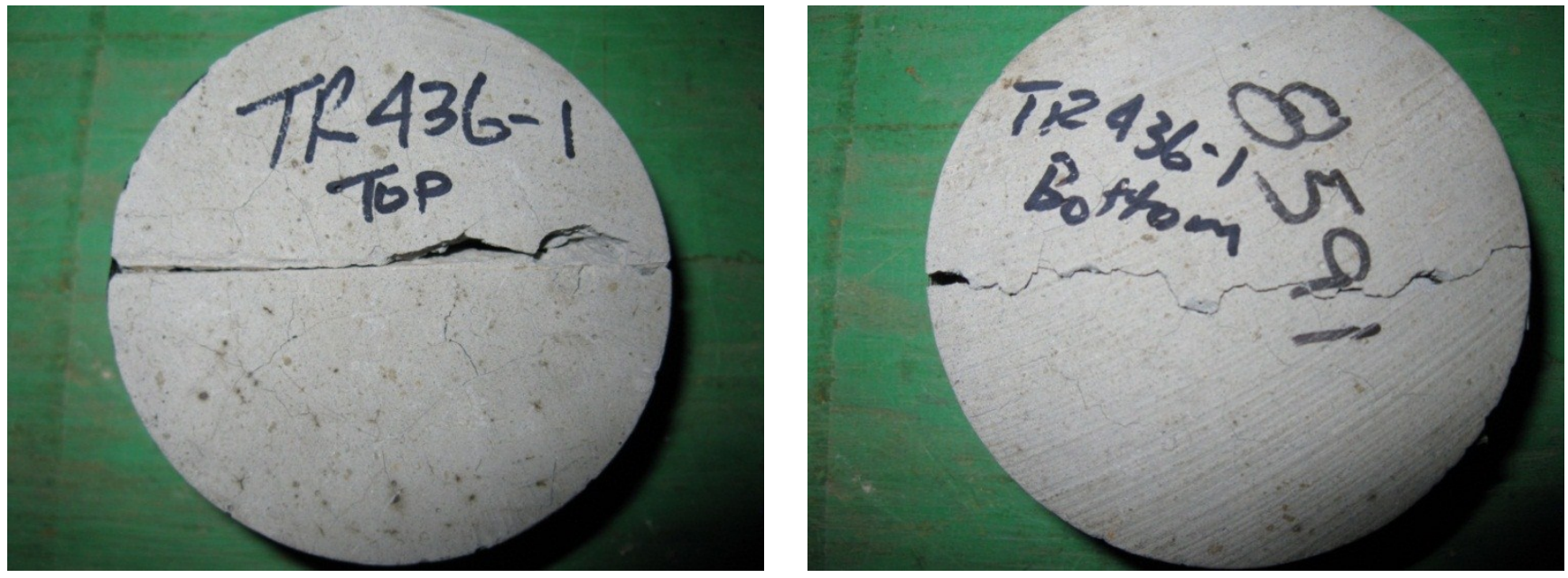

(a)

(b)

Figure 6. Saltstone Sample TR436 with Micro Fracture Network and Fully Penetrating Rough Surface Fracture - Top View (a) and Bottom View (b). 


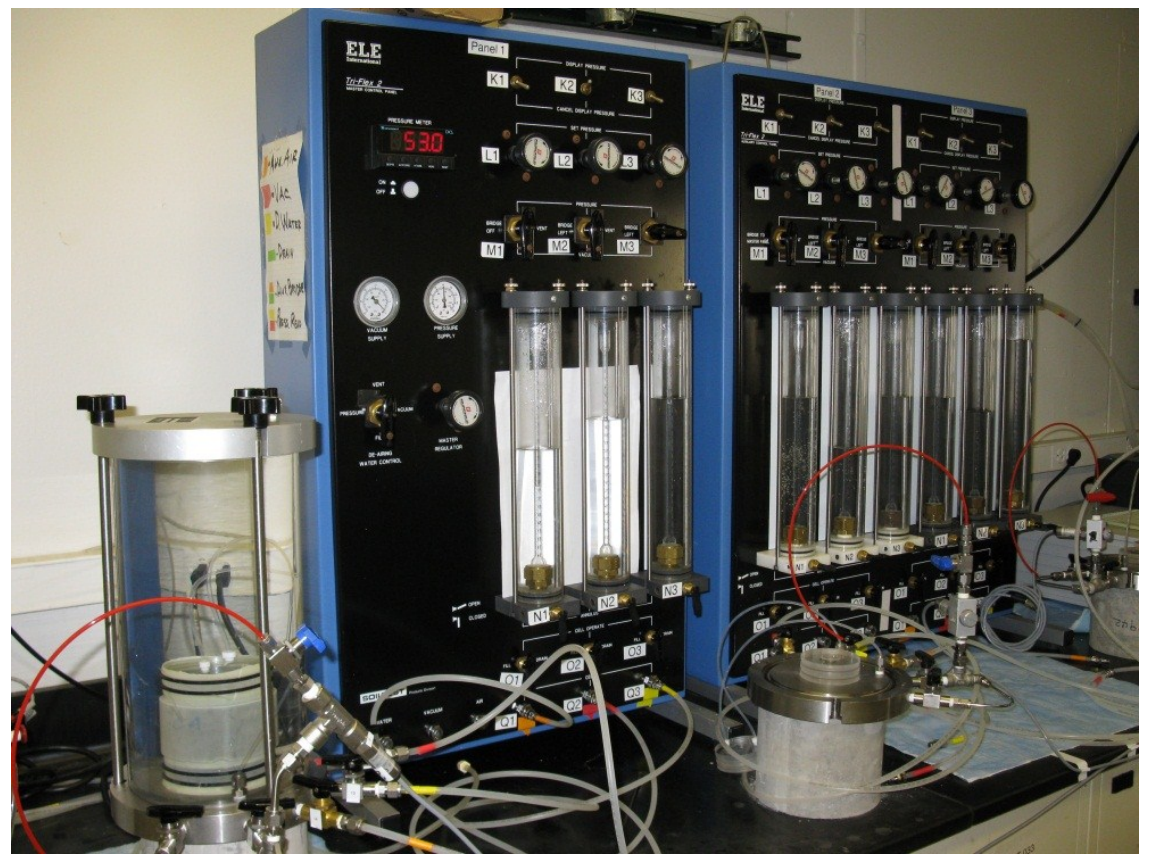

Figure 7. Flexible Wall Permeameter used for Saturated Hydraulic Conductivity Tests (ASTM D 5084).

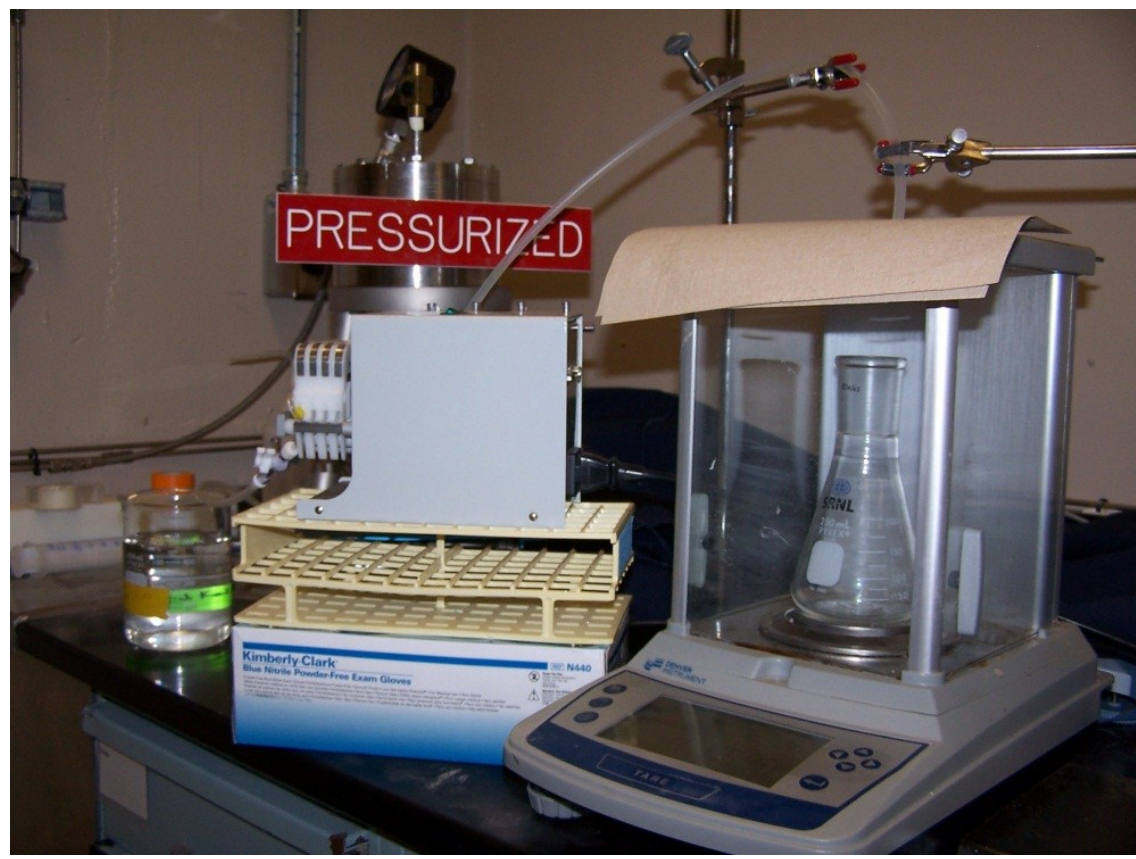

Figure 8. Outflow Extractor, Fraction Collector, Peristaltic Pump, and High Precision Digital Balance used in Transient Outflow Extraction Tests. 


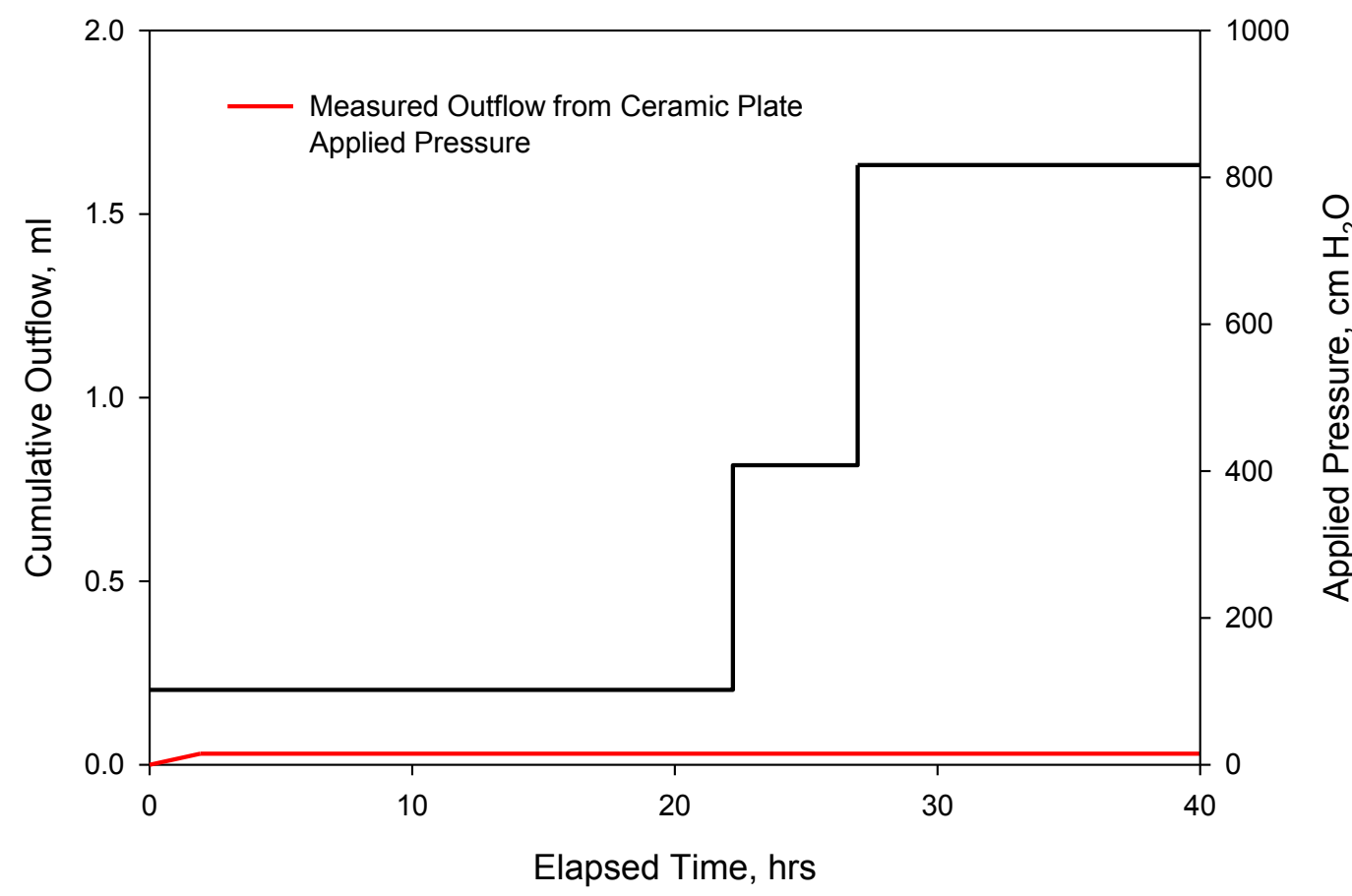

Figure 9. Measured Outflow from Porous Ceramic Plate.

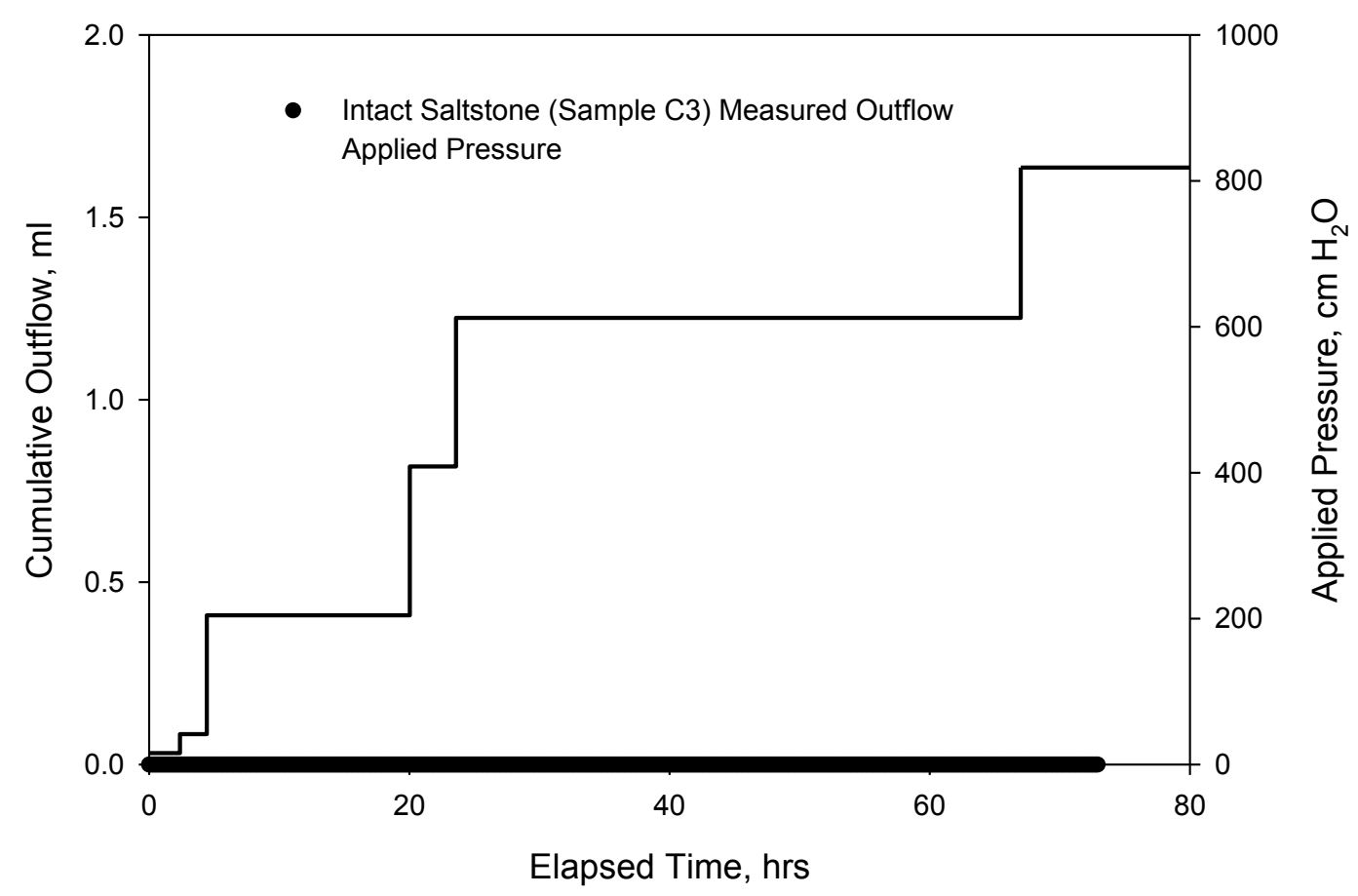

Figure 10. Measured Outflow from Intact Saltstone Sample C3. 


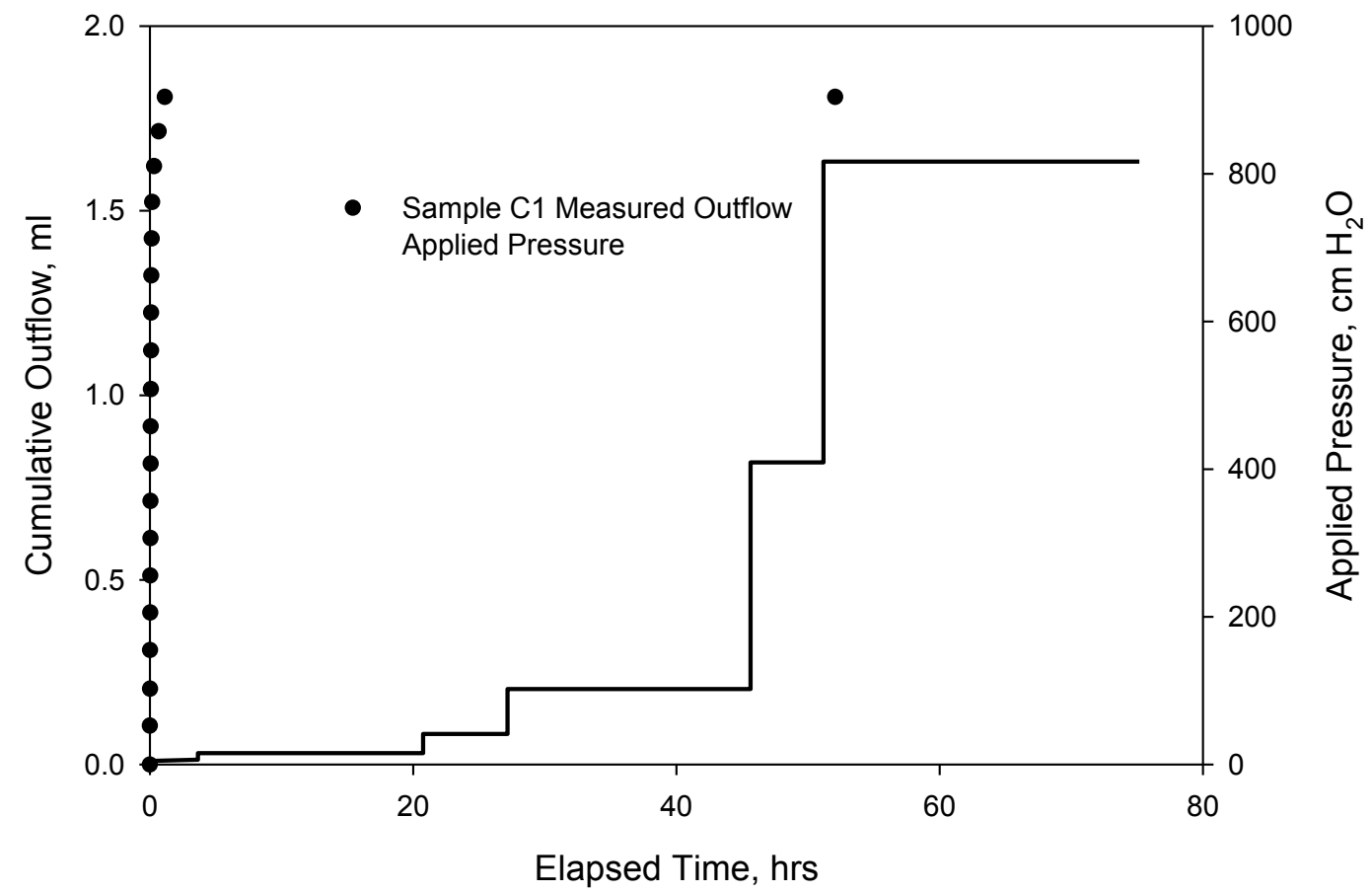

Figure 11. Measured Outflow from Saltstone Sample C1 with Saw Cut Fully Penetrating Smooth Surface Fracture.

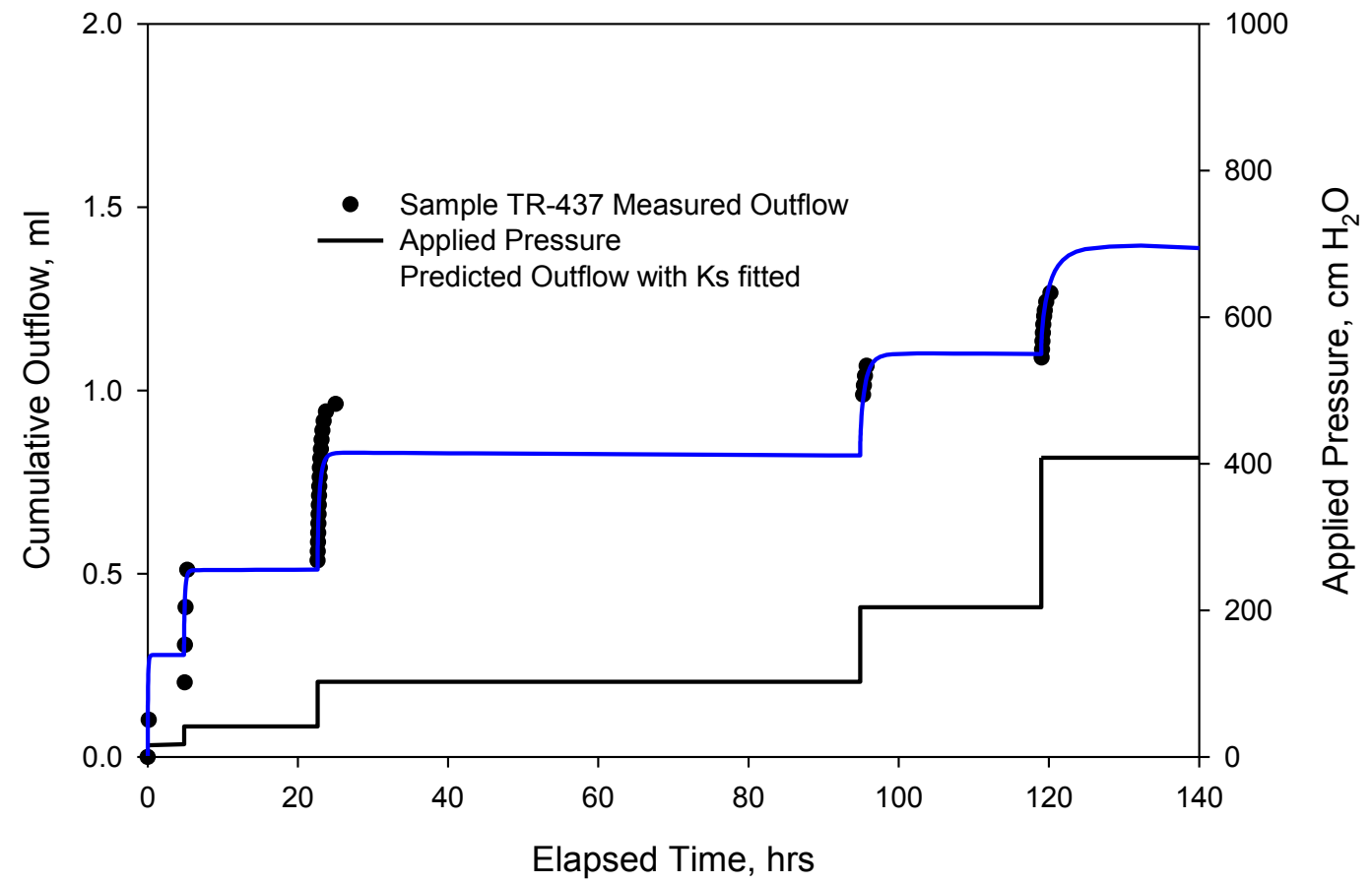

Figure 12. Measured Outflow from Saltstone Sample TR437 with Micro Fractures Created by Oven Drying. 
SRNL-STI-2013-00522

Revision 0

TR437

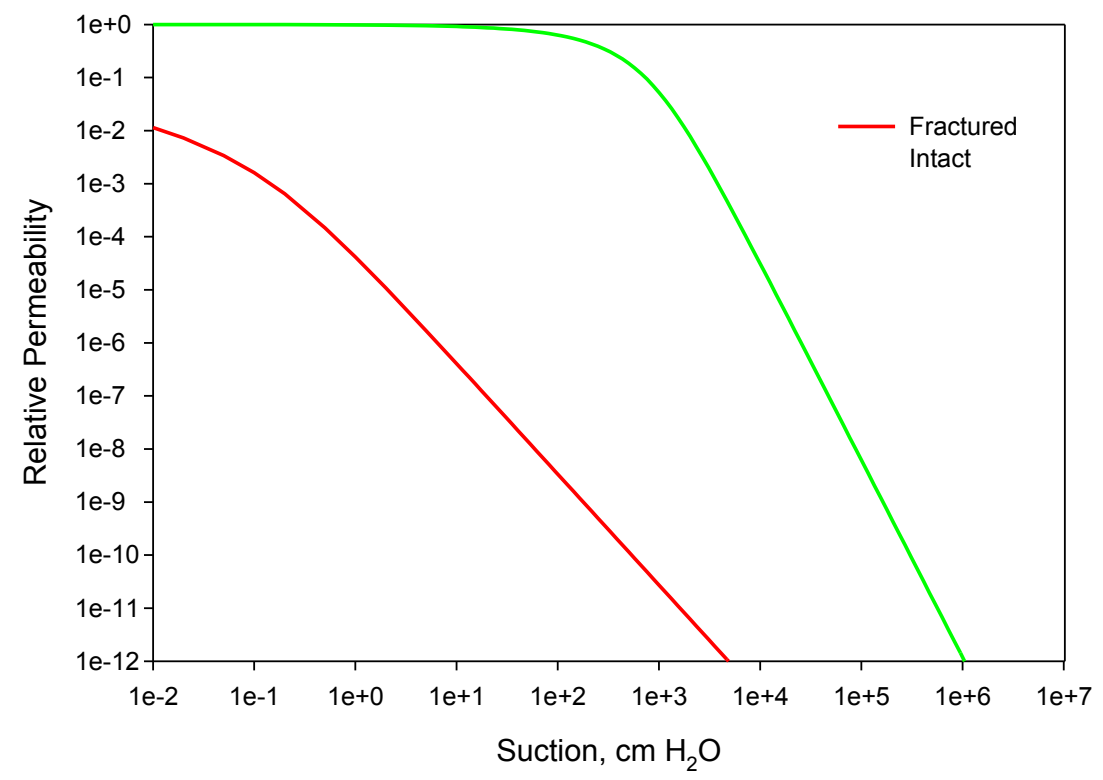

Figure 13. Relative Permeability Curves for Fractured and Intact Saltstone - TR437.

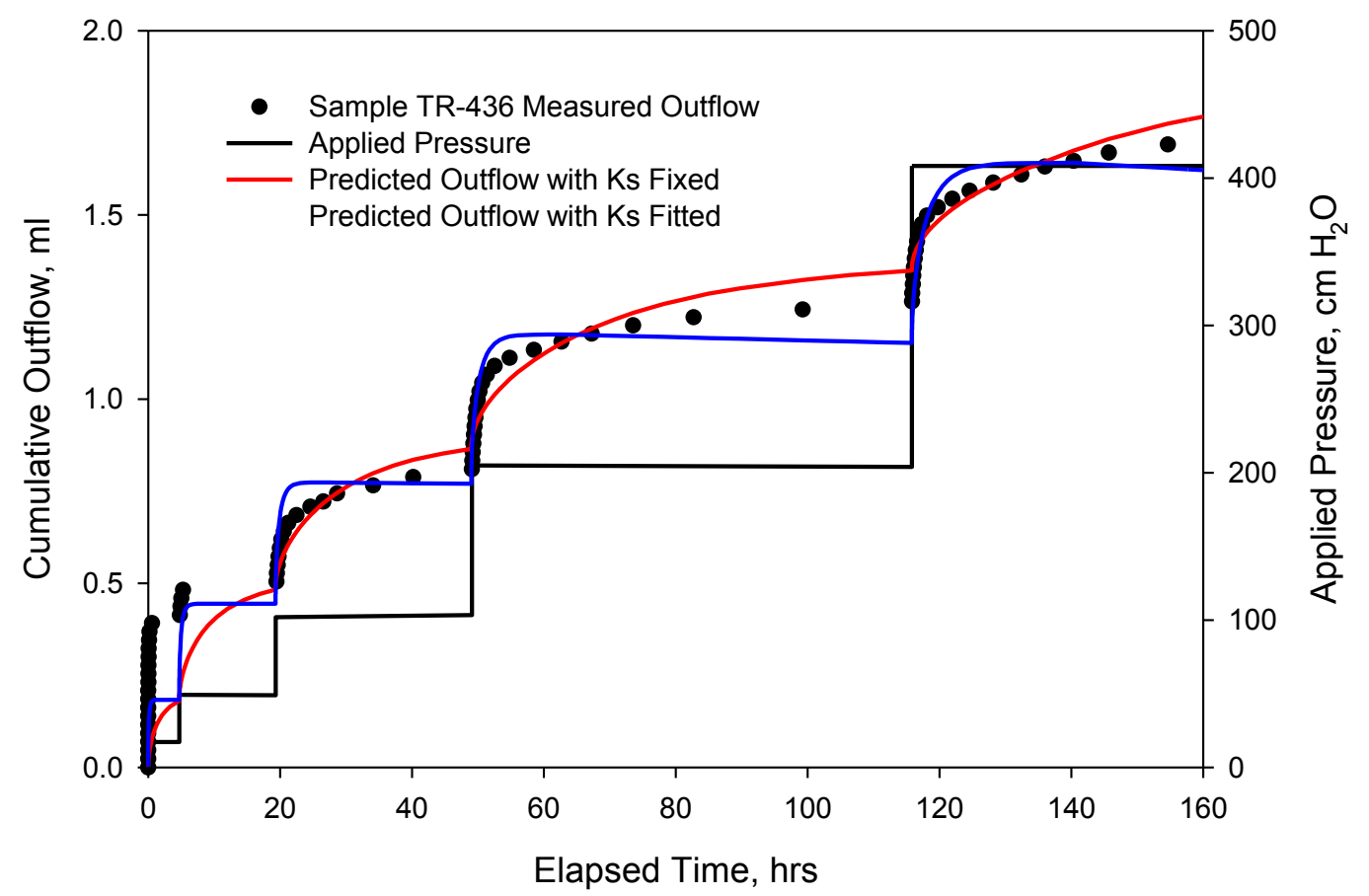

Figure 14. Measured Outflow from Saltstone Sample TR436 with Micro Fractures Created by Oven Drying and with Fully Penetrating Rough Surface Fracture. 
SRNL-STI-2013-00522

Revision 0

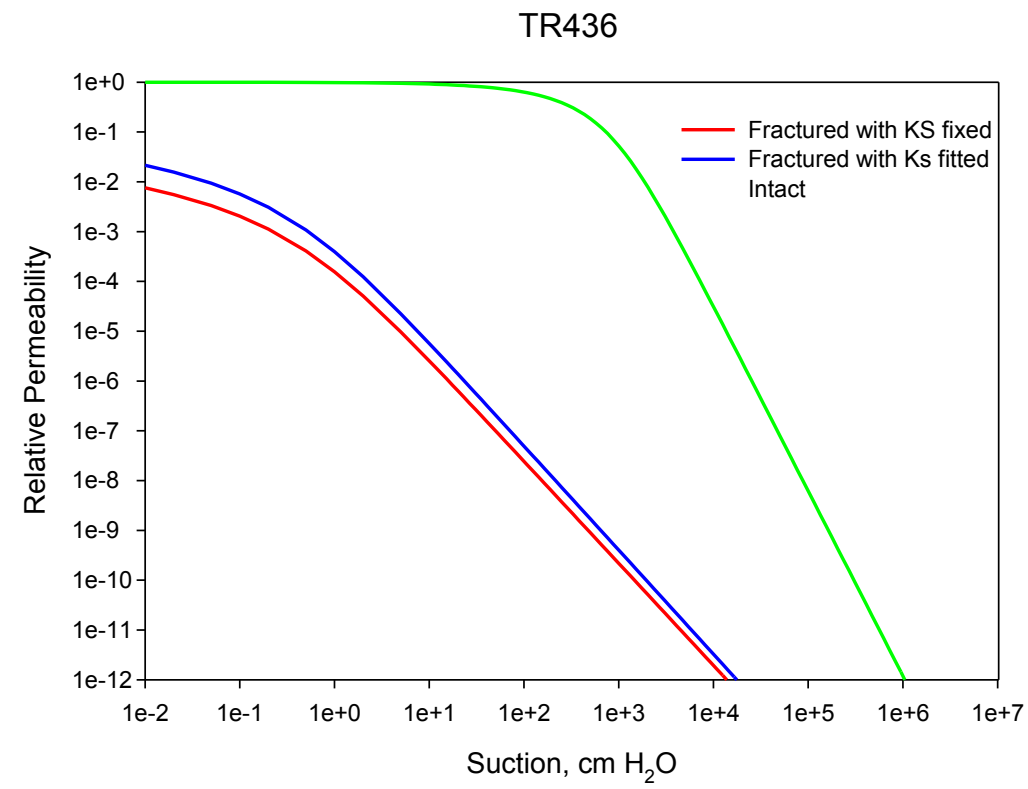

Figure 15. Relative Permeability Curves for Fractured and Intact Saltstone TR-436. 
SRNL-STI-2013-00522

Revision 0

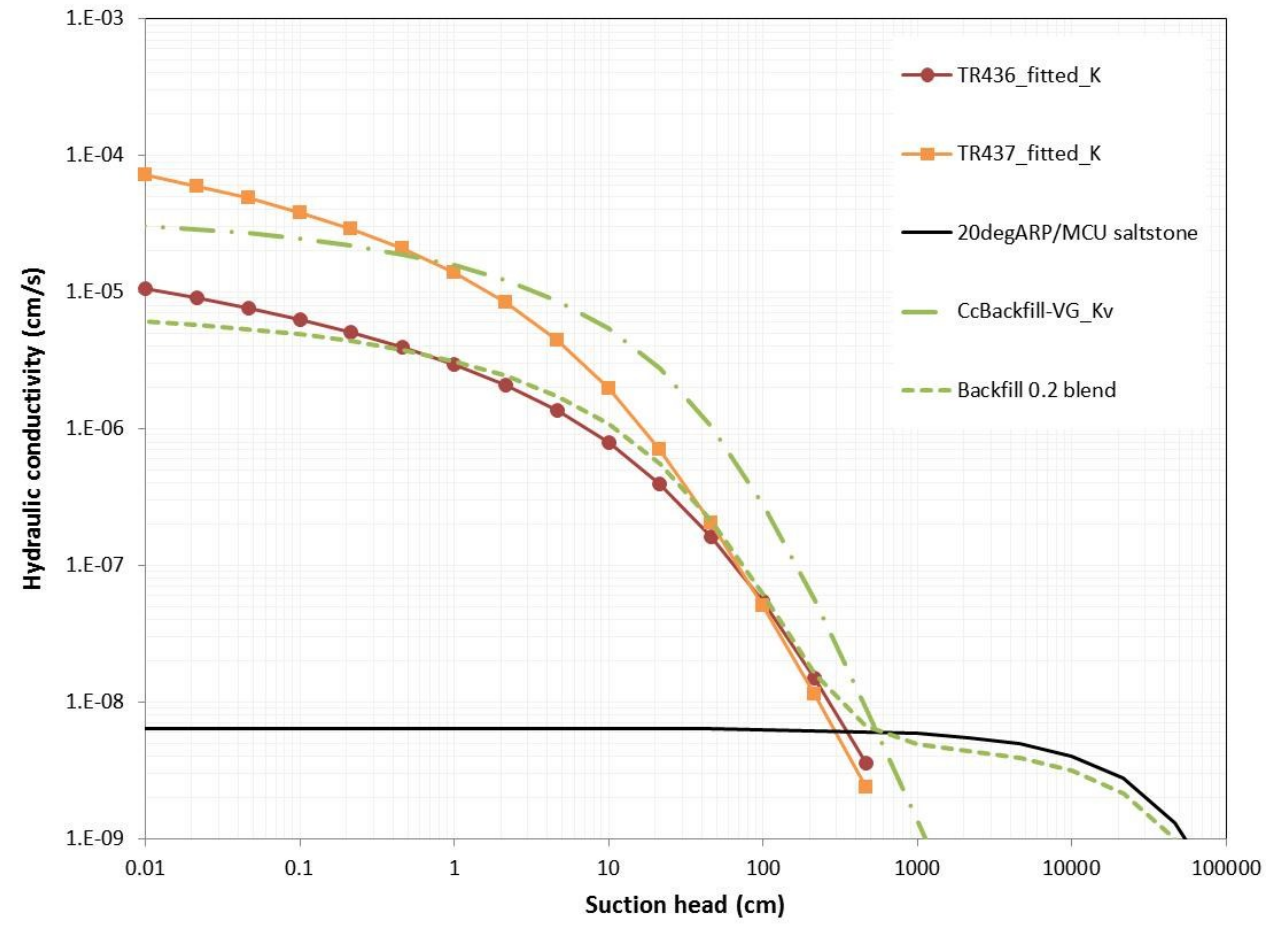

Figure 16. Comparison of Unsaturated Hydraulic Conductivity for Samples TR436 and TR437 to Intact saltstone, Backfill Soil, and a $20 \%$ Backfill (80\% intact saltstone) Blend.

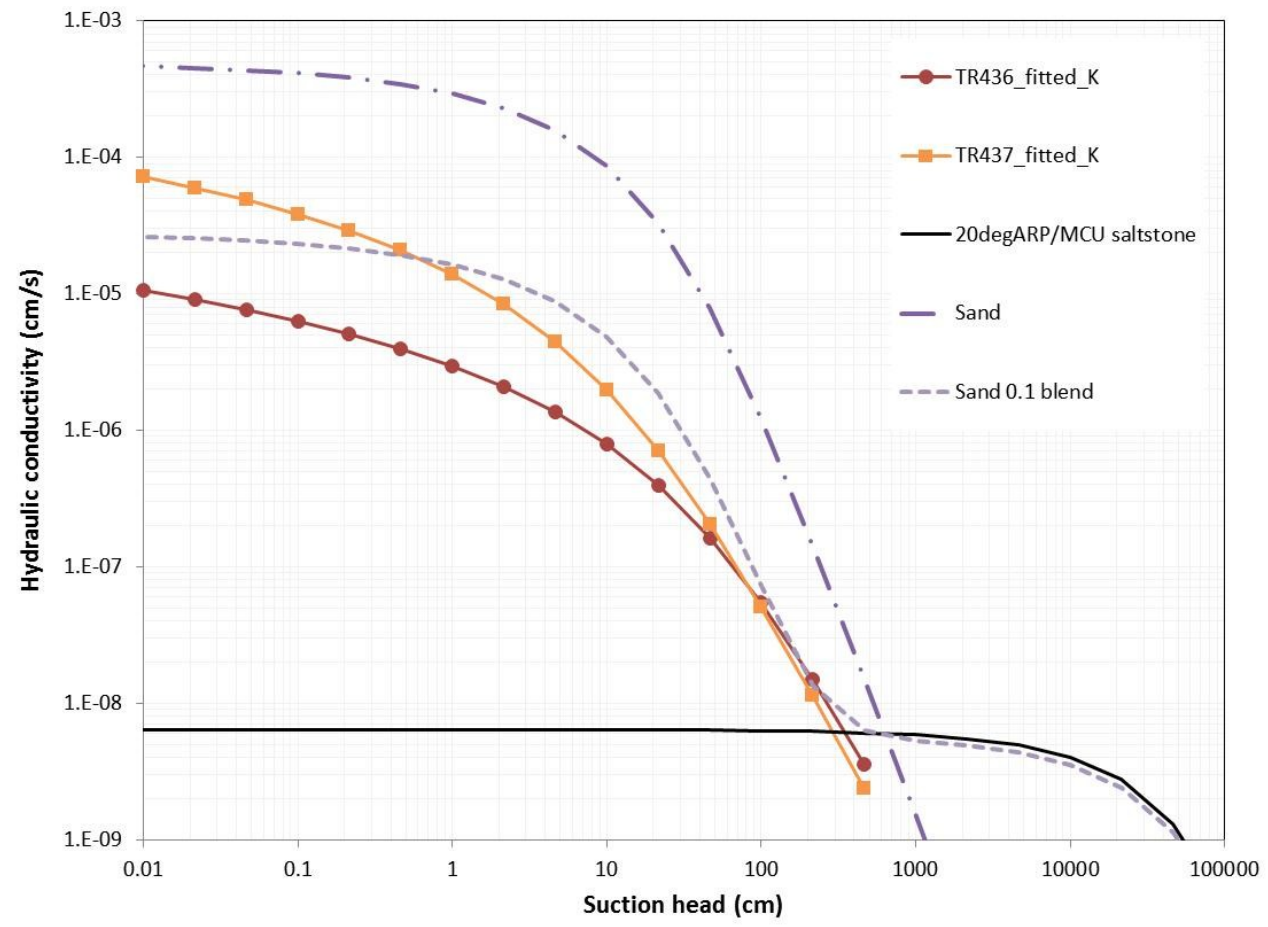

Figure 17. Comparison of TR437 to a $10 \%$ Sand and $90 \%$ Intact Saltstone Blend as An Example of Improved Fit. 

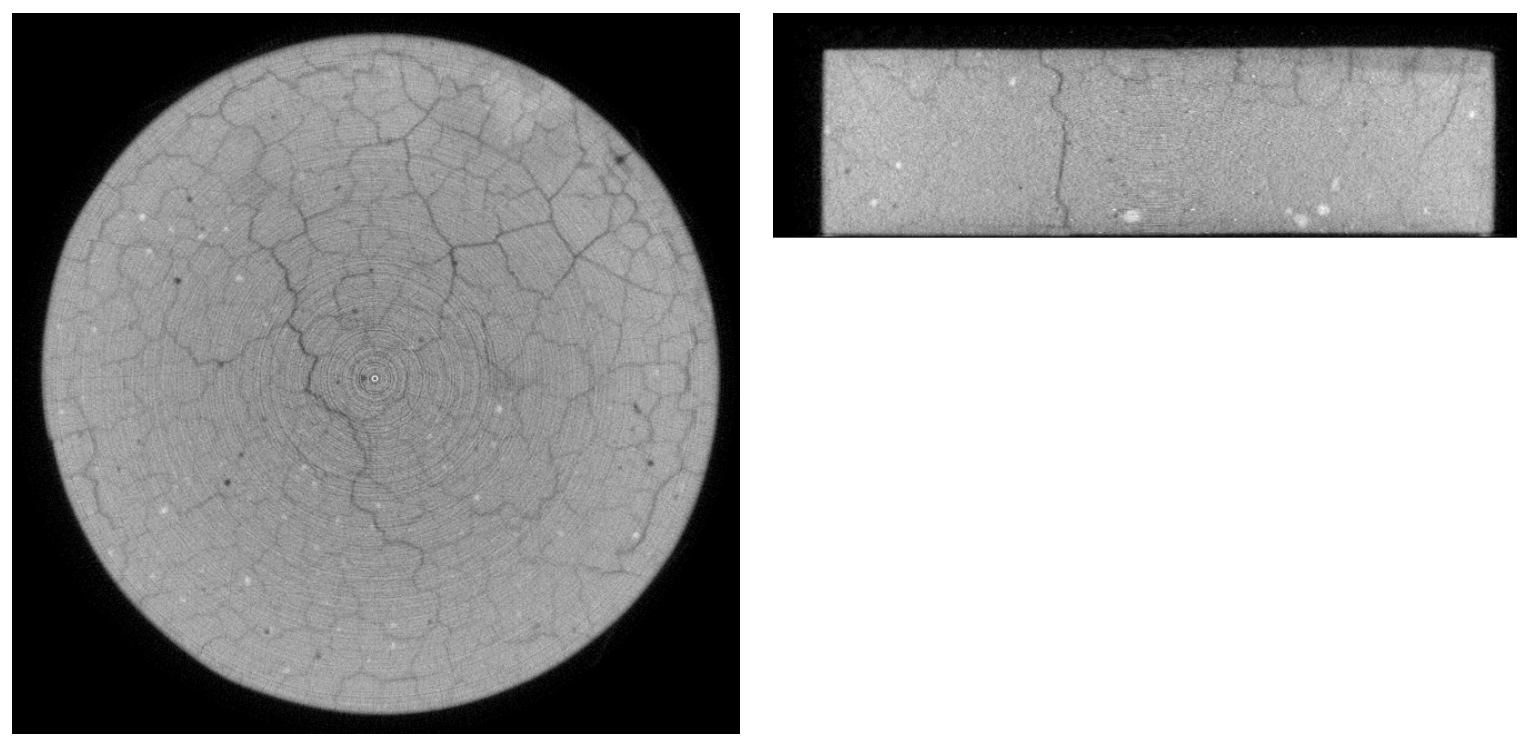

(a)

(b)

Figure 18. Longitudinal (a) and transverse (b) slice of sample TR437 showing microfracture network heterogeneity and large scale porosity as represented by black features $\left(\mathrm{K}_{\mathrm{s}}=1.42 \times 10^{-4} \mathrm{~cm} / \mathrm{sec}\right)$.

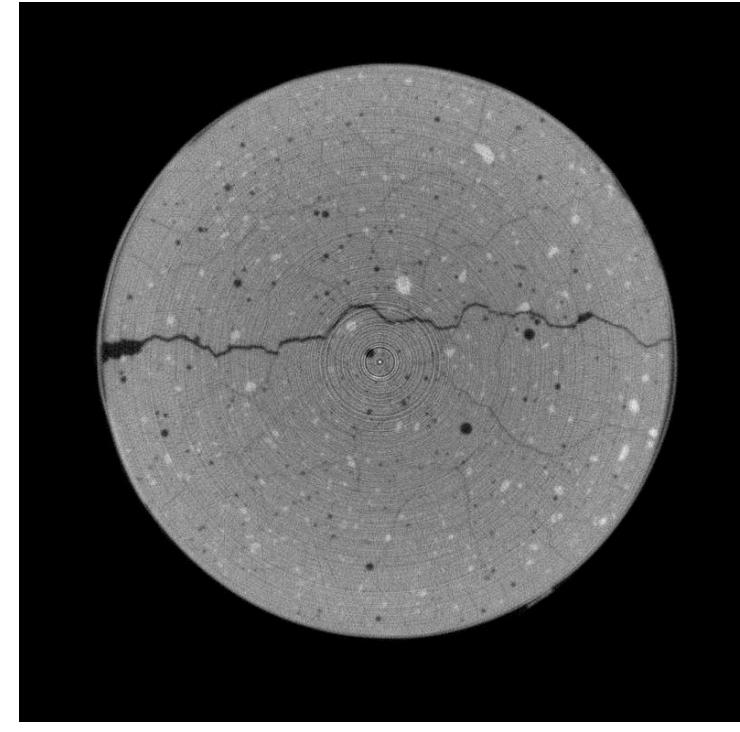

(a)

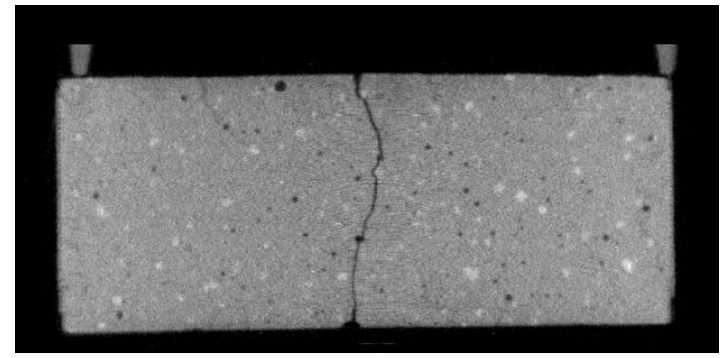

(b)

Figure 19. Longitudinal (a) and transverse (b) slice of sample TR436 showing microfracture network heterogeneity and large scale porosity as represented by black features $\left(K_{s}=1.99 \times 10^{-6} \mathrm{~cm} / \mathrm{sec}\right)$. 
Table 1. Hydraulic Properties of Fractured Saltstone Samples as Measured by SRNL ${ }^{1}$

\begin{tabular}{|c|c|c|c|c|c|c|}
\hline Sample Id & $\begin{array}{c}\text { Intact } \\
\text { Saturated } \\
\text { Hydraulic } \\
\text { Conductivity } \\
(\mathrm{cm} / \mathrm{s})\end{array}$ & $\begin{array}{c}\text { Fractured } \\
\text { Saturated } \\
\text { Hydraulic } \\
\text { Conductivity } \\
(\mathrm{cm} / \mathrm{s})\end{array}$ & $\begin{array}{c}\text { Intact } \\
\text { Dry } \\
\text { Bulk } \\
\text { Density } \\
\left(\mathrm{g} / \mathrm{cm}^{3}\right)^{2}\end{array}$ & $\begin{array}{c}\text { Fractured } \\
\text { Dry } \\
\text { Bulk } \\
\text { Density } \\
\left(\mathrm{g} / \mathrm{cm}^{3}\right)^{2}\end{array}$ & $\begin{array}{c}\text { Intact } \\
\text { Porosity }^{3}\end{array}$ & $\begin{array}{l}\text { Fractured } \\
\text { Porosity }^{3}\end{array}$ \\
\hline Salt C1 & $<1.0 \mathrm{E}-09$ & $8.8 \mathrm{E}-05$ & 0.93 & - & 0.62 & - \\
\hline Salt C3 & $<1.0 \mathrm{E}-09$ & $5.6 \mathrm{E}-06$ & 0.93 & - & 0.62 & - \\
\hline Salt C4 & $<1.0 \mathrm{E}-09$ & - & 0.93 & - & 0.62 & - \\
\hline TR436 & $5.0 \mathrm{E}-09^{\mathrm{a}}$ & $2.0 \mathrm{E}-05$ & $0.98^{\mathrm{a}}$ & 0.85 & $0.58^{\mathrm{a}}$ & 0.62 \\
\hline TR437 & $1.1 \mathrm{E}-09^{\mathrm{a}}$ & $1.4 \mathrm{E}-04$ & $0.95^{\mathrm{a}}$ & 0.86 & $0.59^{\mathrm{a}}$ & 0.59 \\
\hline
\end{tabular}

${ }^{1}$ All properties measured by SRNL except as noted.

${ }^{2}$ Dry bulk density corrected for salt precipitation as described by Dixon (2009).

${ }^{3}$ Porosity corrected for salt precipitation as described by Dixon et al. (2009).

${ }^{\mathrm{a}}$ As reported by Dixon et al. (2008)

Table 2. Van Genuchten Parameters as Determined from Outflow Data using Hydrus ${ }^{\mathrm{a}}$.

\begin{tabular}{|c|c|c|c|c|c|c|c|}
\hline Sample ID & $\begin{array}{c}\boldsymbol{\theta}_{\mathbf{s}} \\
\left(\mathbf{c m}^{\mathbf{3}} / \mathbf{c m}^{-\mathbf{3}}\right)\end{array}$ & $\begin{array}{c}\boldsymbol{\theta}_{\mathbf{r}} \\
\left(\mathbf{c m}^{\mathbf{3}} / \mathbf{c m}^{\mathbf{3}}\right)\end{array}$ & $\begin{array}{c}\boldsymbol{\alpha} \\
(\mathbf{1} / \mathbf{c m})\end{array}$ & $\mathbf{n}$ & $\mathbf{m}$ & $\begin{array}{c}\mathbf{K}_{\mathbf{s}} \\
(\mathbf{c m} / \mathbf{s e c})\end{array}$ & $\mathbf{r}^{\mathbf{2}}$ \\
\hline PA & 0.600 & 0.00492 & 0.00001 & 1.6861 & 0.4069 & $6.40 \mathrm{E}-09$ & - \\
\hline TR436 & $0.615^{\mathrm{b}}$ & 0.11209 & 0.01129 & 1.0203 & 0.0199 & $1.99 \mathrm{E}-05^{\mathrm{b}}$ & 0.979 \\
\hline TR436 & $0.615^{\mathrm{b}}$ & 0.38784 & 0.0126 & 1.0361 & 0.0348 & $1.38 \mathrm{E}-04^{\mathrm{c}}$ & 0.977 \\
\hline TR437 & $0.592^{\mathrm{b}}$ & 0.42109 & 0.04563 & 1.0361 & 0.0348 & $1.22 \mathrm{E}-03^{\mathrm{c}}$ & 0.951 \\
\hline
\end{tabular}

${ }^{\mathrm{a}}$ Data analyzed using Mualem relationship between $\mathrm{n}$ and $\mathrm{m}$ where $\mathrm{m}=1-1 / \mathrm{n}$.

${ }^{\mathrm{b}}$ Set to the measured material property

${ }^{\mathrm{c}}$ Fitted value

Table 3. Comparison of Measured and Predicted Hydraulic Properties for TR436 and TR437.

\begin{tabular}{|c|c|c|}
\hline & $\begin{array}{c}\text { Measured Hydraulic } \\
\text { Conductivity } \\
\text { (cm/sec) }\end{array}$ & $\begin{array}{c}\text { Hydrus-1D Predicted Hydraulic } \\
\text { Conductivity } \\
\text { (cm/sec) }\end{array}$ \\
\hline TR436 & $1.99 \mathrm{E}-05$ & $1.38 \mathrm{E}-04$ \\
\hline TR437 & $1.42 \mathrm{E}-04$ & $1.22 \mathrm{E}-03$ \\
\hline
\end{tabular}




\section{Distribution:}

D. A. Crowley, 773-43A

T. O.Oliver, 773-42A

G. P. Flach, 773-42A

R. L. Nichols, 773-42A

K. L. Dixon, 773-42A

K. H. Rosenberger, 705-1C

S. P. Simner, 249-8H 
SRNL-STI-2013-00522

Revision 0

\section{APPENDIX A. SRNL-L3200-2012-00029_R0}


SRNL-STI-2013-00522

Revision 0

(1) SRNL

SRNL-L3200-2012-00029_R0

April 15, 2012

To:

David Crowley, 773-43A

From:

J. L. Kohn, 773-42A

K. L. Dixon 773-42A

R. L. Nichols $773-42 \mathrm{~A}$

Re: $\quad$ Fractured media update

INTRODUCTION

This work proceeded in accordance with SRNL-TR-2012-00090: TTQAP for Determining the Unsaturated Permeability of Fractured Saltstone (Flach, 2012). It addressed the method development portion of sub-task 3 listed in Section 2.1 of the above document. This work represented a proof-ofconcept for the fracture analog and the test method.

\section{PROCEDURE}

\section{FRACTURE ANALOG}

In order to simulate a fractured medium, an appropriate analog was developed. Microscope slides were selected as a likely candidate and several configurations were evaluated. This included assembling blocks of microscope slides with spacers at both ends and spacers at alternating ends. The spacer chosen was laboratory tape. Blocks consisted of 15 slides each and represented 14 fractures. Blocks were secured using adhesive tape, leaving the long edges exposed. Six blocks were prepared, three each of both ends spaced or alternating ends spaced, to simulate both constant and variable-width fractures. Blocks were vacuum-saturated with DI water, weighed, oven-dried at $105^{\circ} \mathrm{C}$, and weighed again to determine the mass and volume of water contained within the blocks.

TEST APPARATUS

Several apparatus were considered for use in these tests. Two pressure plate extractors of different pressure ratings, a hanging column apparatus, and an outflow extractor were compared and evaluated based on maximum sample size, availability of equipment, and ease of implementation. An outflow extractor previously used to characterize sediments (Dixon 2011) was ultimately selected as suitable for the fracture analog size and quantity of outflow expected. Maximum sample size is 3 in. diameter and 3 in. height.

TESTING

Experimental method followed the outflow extractor method, detailed in (Dixon 2011) and illustrated in Figure 1. This set-up was modified to use an analytical balance and desktop pc to log mass readings over

\section{We Put Science To Work}

The Savannah fiver National Laboratory is managed and operated for the US. Department of Energy by

SAVANNAH RIVER NUCLEAR SOLUTIONS, LLC

AIKEN, SS USA 29808 - SRNL,DQE,GQV 
SRNL-STI-2013-00522

Revision 0

SRNL-L3200-2012-00029_R0

time. The samples were exposed to increasing pressure steps and the mass of the water flowing out of the sample was logged electronically. As this was a proof-of-concept study, not all experimental parameters were well-defined at the beginning of the study. Length of test, maximum pressure, and magnitude and duration of pressure steps varied between tests to identify appropriate parameters for future tests. A generic procedure follows:

- Fracture analog (slide block) to be examined was saturated in DI water under vacuum

- Porous plate in outflow extractor was saturated under pressure, and bubbles were removed from bottom of plate.

- Sample was loaded into outflow extractor, Figure 2, and lid-bolts were tightened to specified torque.

- Pressure to be applied was dialed in at pressure application manifold and instantaneously applied to extractor.

- Pressure was verified with digital gage attached to outflow extractor.

- Outflow was digitally logged via connection to pc on 5-second intervals.

- The previous three steps were repeated until the maximum test pressure was reached.

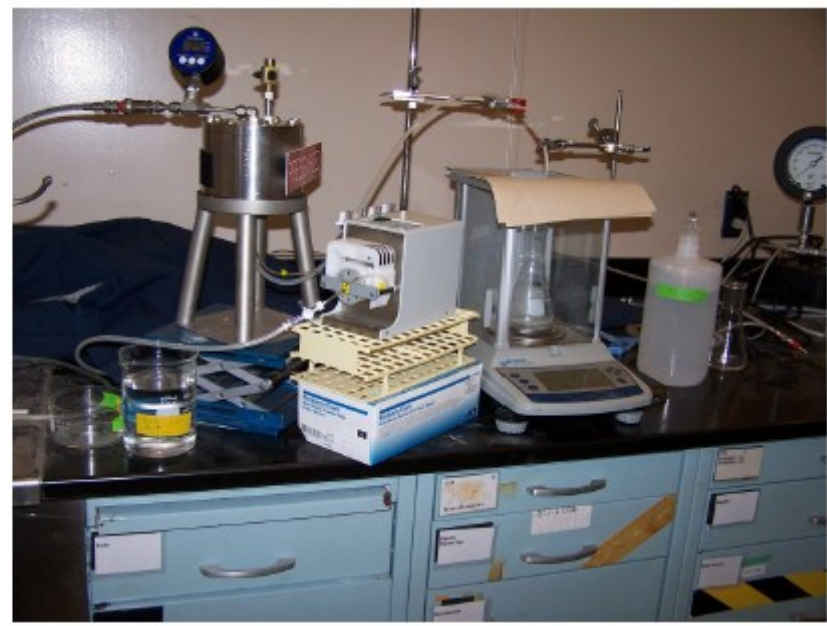

Figure 1: Outflow extractor setup 
SRNL-STI-2013-00522

Revision 0

SRNL-L3200-2012-00029_R0

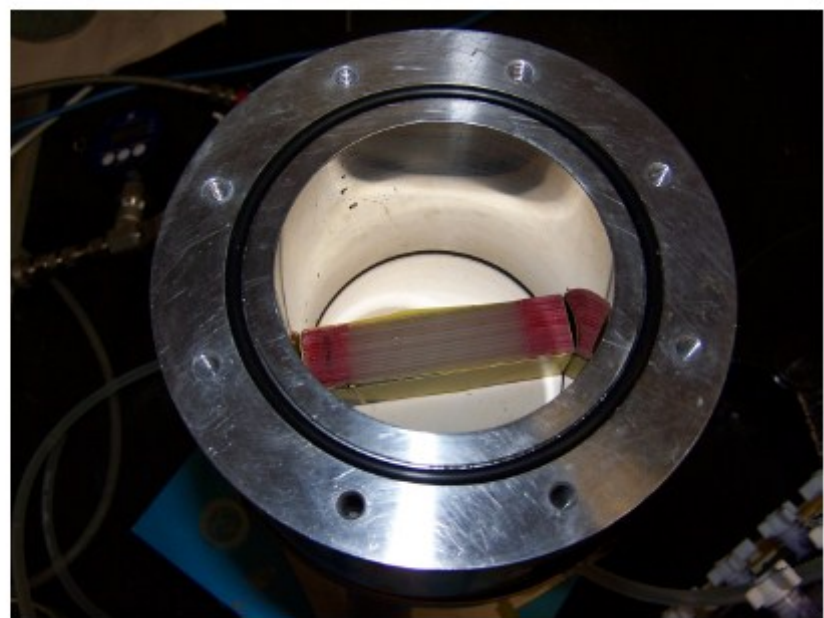

Figure 2: Fracture analog ready to test in outflow extractor

\section{RESULTS}

The digital mass logs were subsequently plotted as a function of elapsed time for the each test. Tests 2 , 3 , and 4 are presented in Figure 3, Figure 4, and Figure 5 respectively. Blue points represent values measured by the balance. Red points represent the cumulative mass of water drops collected from the outflow extractor. Green points represent the pressure of each step. Test 1 was performed on a balance only accurate to $0.1 \mathrm{~g}$, and the results of that particular run were not of sufficient quality to present in this document 
SRNL-STI-2013-00522

Revision 0

SRNL-L3200-2012-00029_R0

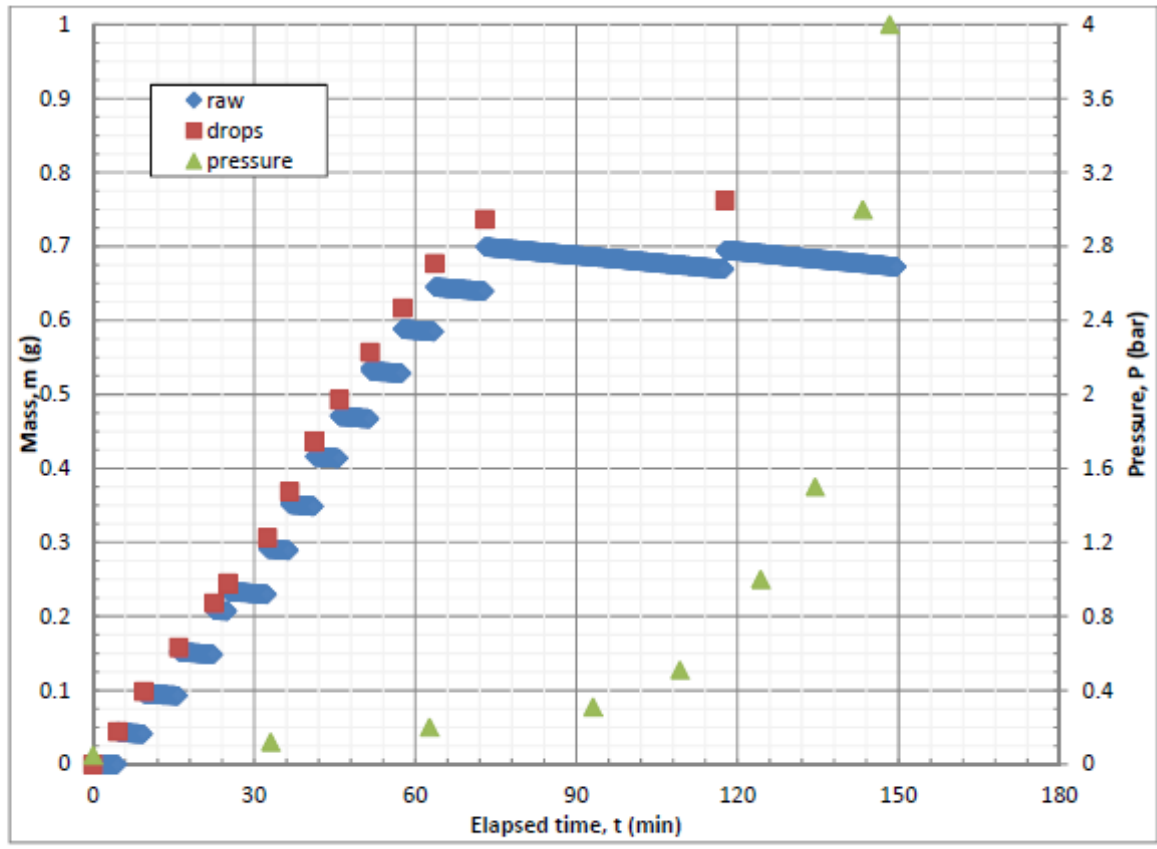

Figure 3: Test 2 Results 
SRNL-STI-2013-00522

Revision 0

SRNL-L3200-2012-00029_R0

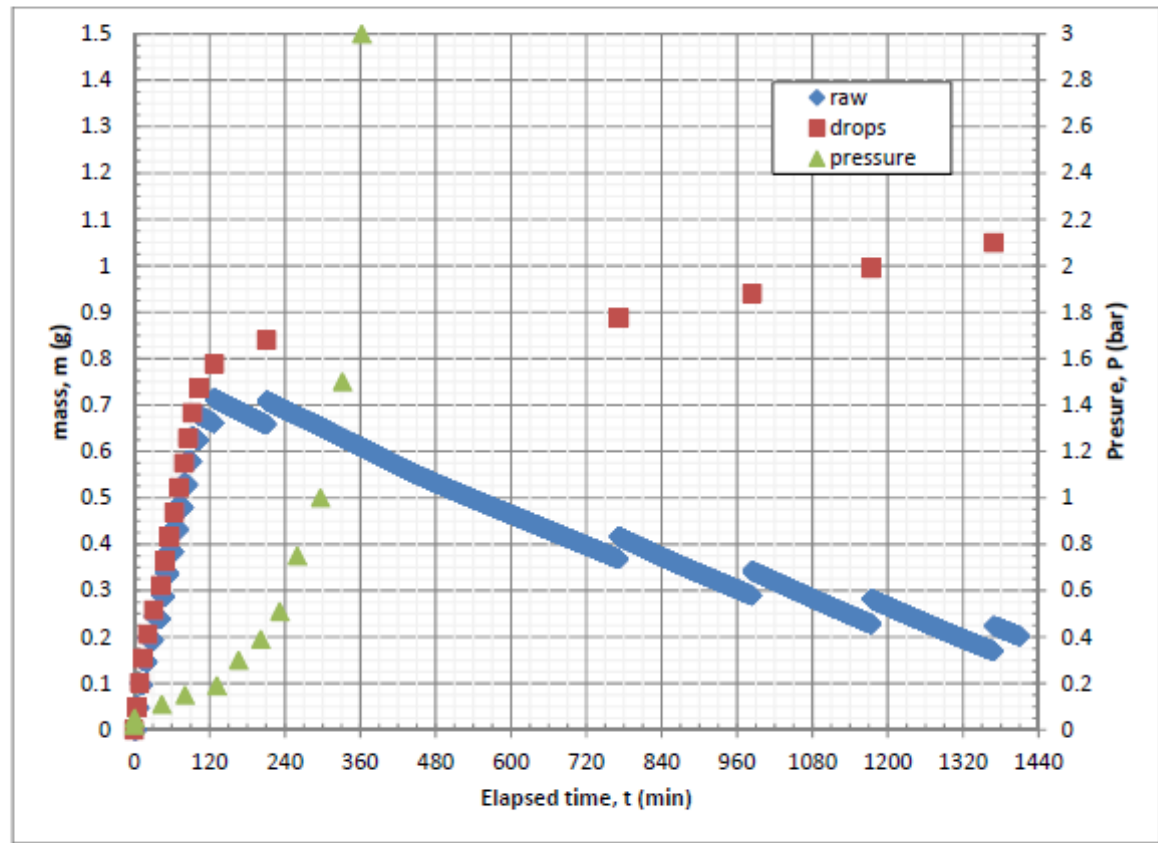

Figure 4: Test 3 results 
SRNL-STI-2013-00522

Revision 0

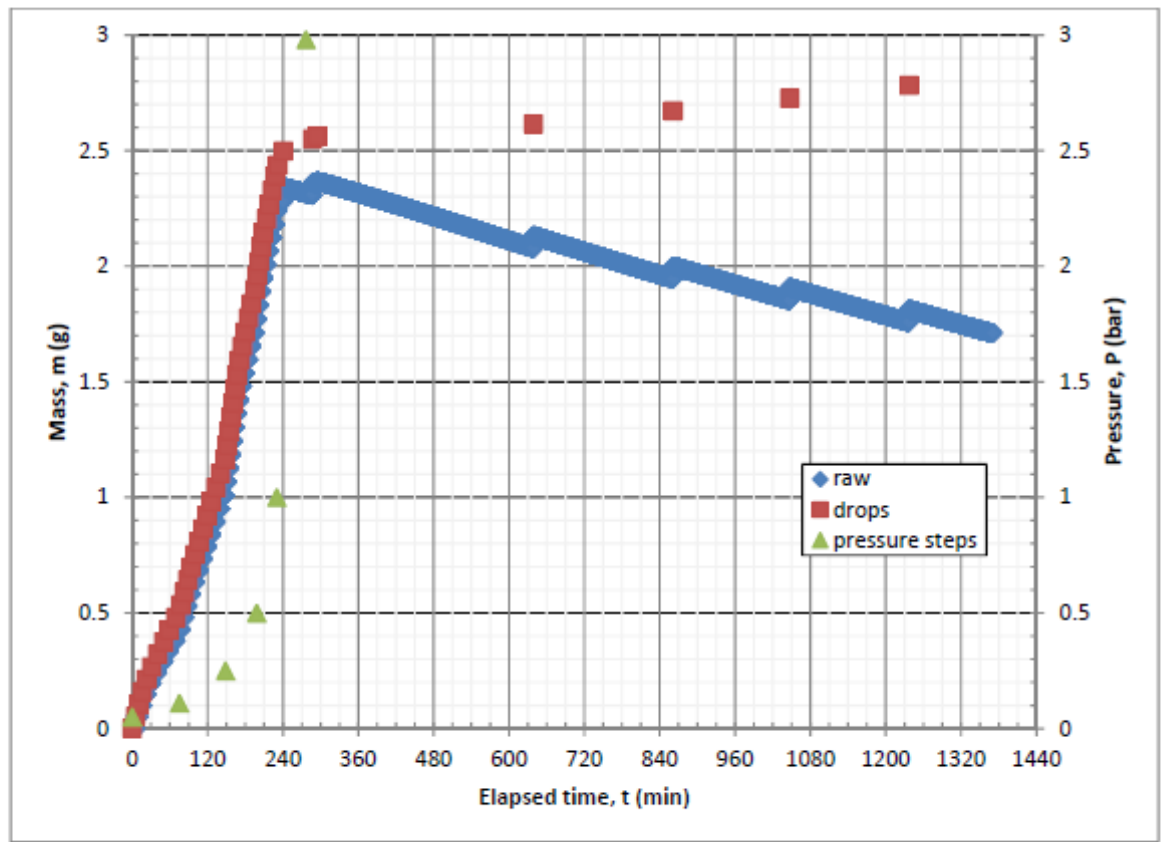

Figure 5: Test 4 results

\section{OBSERVATIONS}

Evaporation was a significant component to the raw data plots. Note the downward trend of the blue points in between mass increases.

Tests 2 and 3 used blocks of slides with alternating spacers leading to a variable aperture fracture. Test 4 used a block of slides with spacers at both ends which yielded a uniform fracture aperture.

The mass of water collected from the outflow extractor was within 10 percent of the mass expected by comparing the mass of the block when saturated and after completion of the test for tests 3 and 4 . Some of the discrepancy could be due to evaporation.

\section{NEXT STEPS}

These data will be analyzed with the software Hydrus to back out the hydraulic properties of the fracture analogs. A disk of cementitious material with known hydraulic properties was fractured by applying a controlled shear stress across the thickness of the disk. This disk was bound back together using adhesive tape and a hose clamp. This sample is presented in Figure 6 , and it will be tested as part of the future of this project. Other fracture methods are being considered for several other cementitious disks. Methods to limit the evaporation from the block inside the extractor, from hanging drops, and from the collection vessel are being considered. 
SRNL-STI-2013-00522

Revision 0

SRNL-L3200-2012-00029_R0

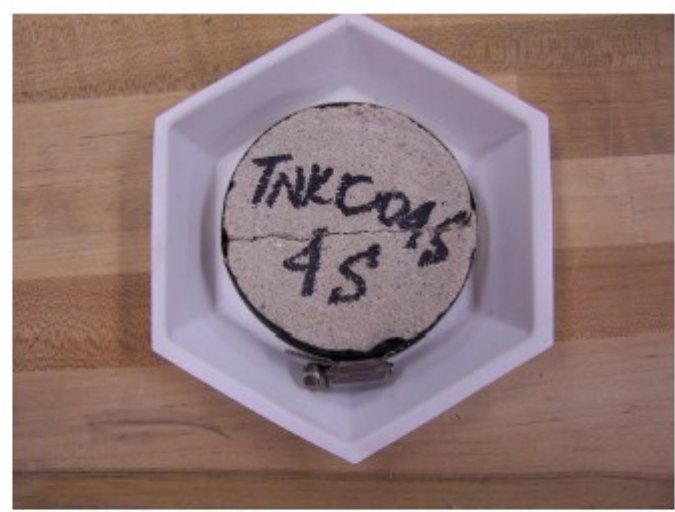

Figure 6: Fractured cementitious material

\section{REFERENCES}

Flach, G. , R. Nichols, and K. Dixon. TTQAP for Determining the Unsaturated Penmeability of Fractured Saltstone. SRNL-TR-2012-00090, Rev.0, March 2012.

Dixon, K. Estimating Hydraulic Properties For E-Area Sediments Using A Multi-Step Outflow Extraction Method. SRNL-STI-2010-00655, Rev. 0. February 2011.

cc: H. Burns, $773-41 \mathrm{~A}$

G. P. Flach, $773-42 \mathrm{~A}$ 
SRNL-STI-2013-00522

Revision 0

\section{APPENDIX B. Saturated Hydraulic Conductivity Data Sheets}


SRNL-STI-2013-00522

Revision 0

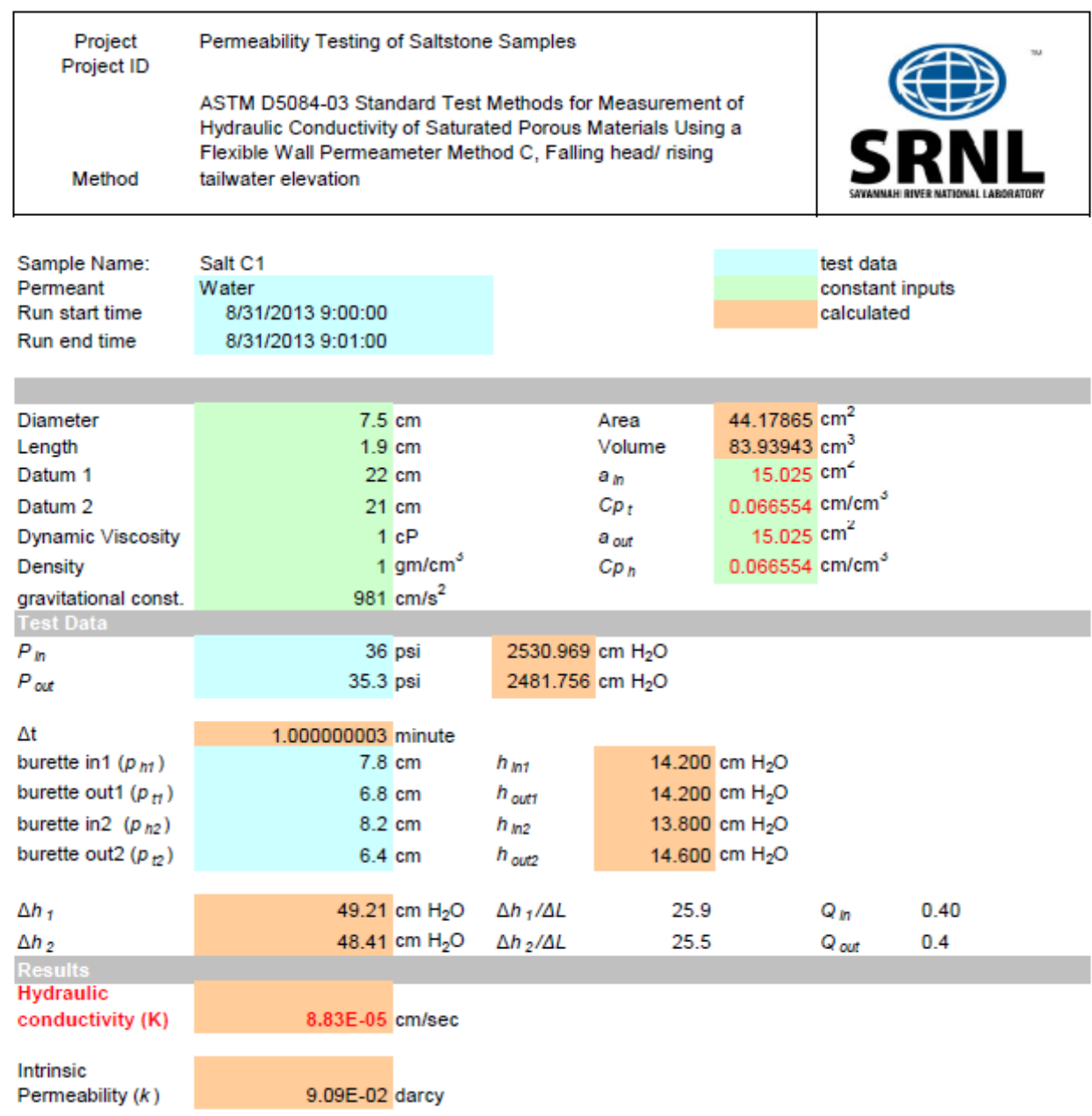


SRNL-STI-2013-00522

Revision 0

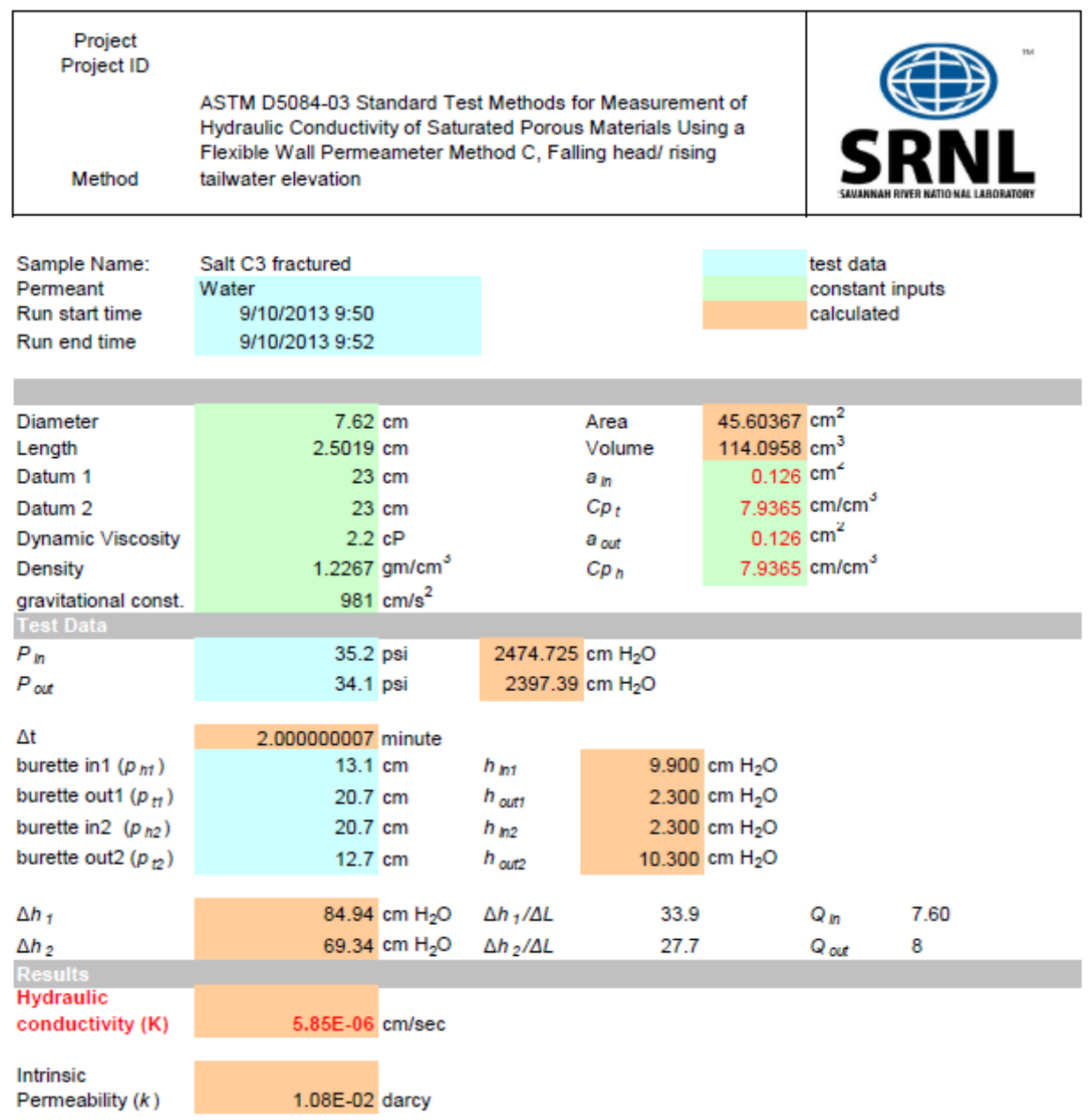


SRNL-STI-2013-00522

Revision 0

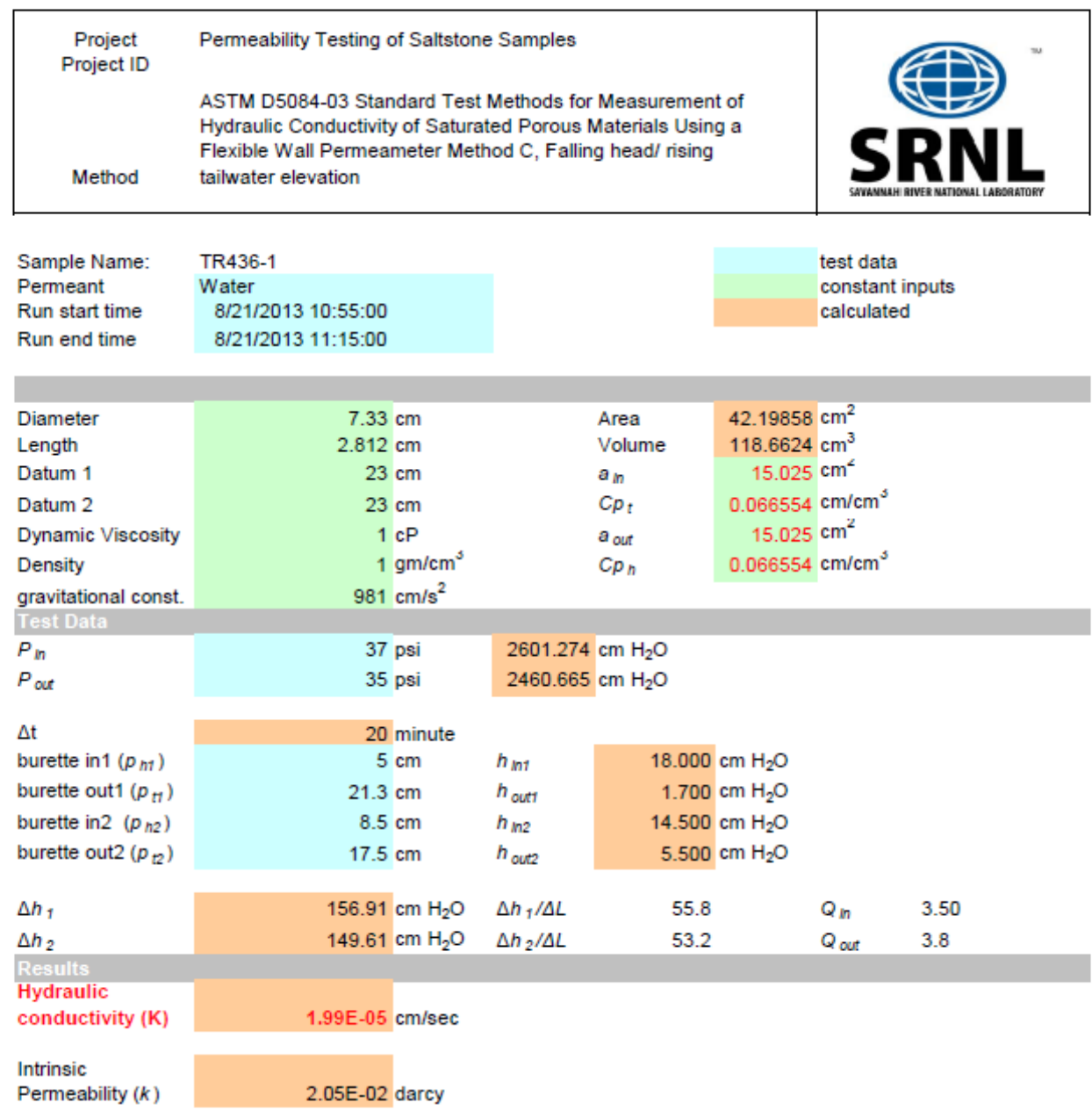


SRNL-STI-2013-00522

Revision 0

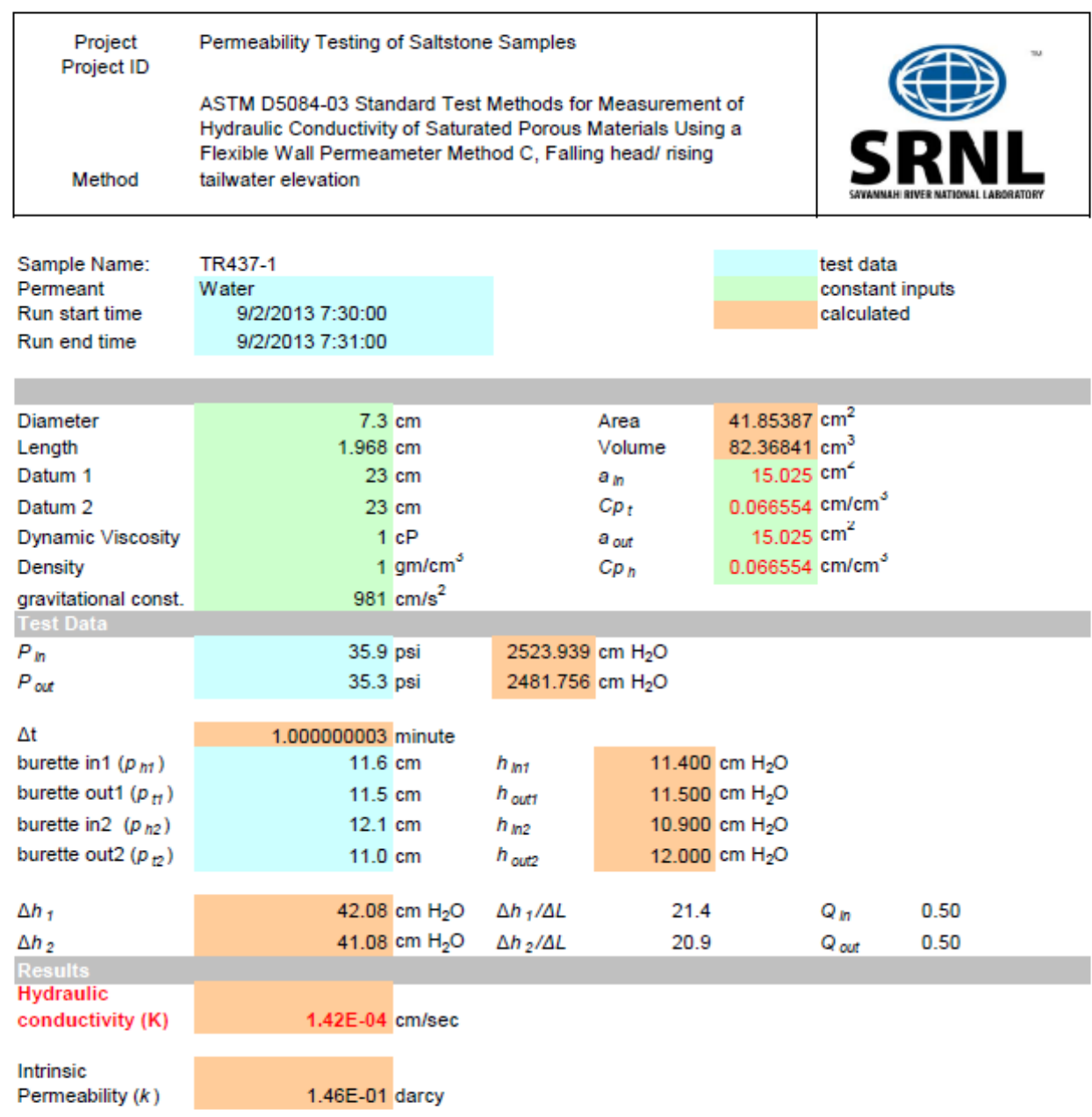

